Running head: STRENGTHS-BASED COACHING

\title{
A CASE STUDY OF BUILDING LEADERS' EXPERIENCES WITH STRENGTHS-BASED COACHING AND FEEDBACK
}

\author{
A Dissertation \\ presented to \\ the Faculty of the Graduate School \\ at the University of Missouri-Columbia \\ In Partial Fulfillment \\ of the Requirements for the Degree \\ Doctorate of Educational Leadership and Policy Analysis \\ by \\ STACI L. JOHNSON \\ Dr. Lisa Dorner, Dissertation Supervisor \\ MAY, 2021
}


The undersigned, appointed by the Dean of the Graduate School, have examined the dissertation entitled

\section{A CASE STUDY OF BUILDING LEADERS' EXPERIENCES WITH STRENGTHS-BASED} COACHING AND FEEDBACK

Presented by Staci L. Johnson

A candidate for the degree of doctor of Educational Leadership and Policy Analysis, and hereby certify that, in their opinion, it is worthy of acceptance.

Dr. Lisa Dorner

Dr. James Sebastian

Dr. Beth Whitaker

Dr. Todd Whitaker 


\section{ACKNOWLEDGEMENTS}

My doctoral journey was only made possible by the unwavering love and support of my family. To my husband, who added more to his already overflowing plate of duties so that I could accomplish this goal, now it's your turn — the next cohort starts this summer! Thank you for listening to stories about professors and classmates and educational theorists and asking follow-up questions to show how much you cared.

To my children, your earliest memories will be of mom furiously typing on her laptopno one asked your permission to sacrifice time with your mommy; thank you for always being there with a hug and a snack when I needed a break. And to my parents, Wanda and Kelly Hinshaw, and my in-laws, Stan and Donna Johnson, thank you for engraining in me the value of hard work and perseverance. Thank you for an endless supply of encouragement and babysitting services. You are the best educators and leaders I know, and making you proud is a driving force in all that I do.

Thank you to the University of Missouri and my dissertation committee for your guidance, and especially to Dr. Lisa Dorner. Throughout this process, you knew exactly when to challenge, when to comfort, when to criticize, and when to encourage. And you did it all through Zoom, which is very impressive.

To my classmates, especially the Capitol City Cohort, thank you for sharing this wonderful, trying, sometimes weird experience with me. I am constantly inspired by each of you. To the high school teachers who taught me how to write, the college professors who opened my eyes to the broader context of educational leadership, and Mrs. Nancy "Sunshine" Culver, my kindergarten teacher who instilled in me a love of learning, I share this moment with you. 
None of this would be possible, none of it would even be worthwhile, if not for the love and grace of my redeeming Father, who is the ultimate source of strength. To him be the glory. 
Table of Contents

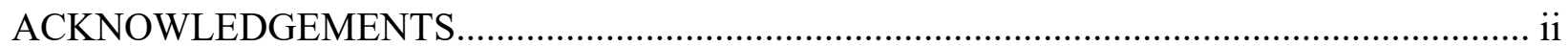

LIST OF TABLES AND FIGURES ..............................................................................

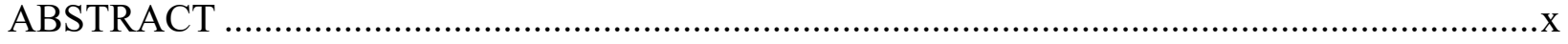

Section One: Introduction to the Dissertation-in-Practice.................................................... 1

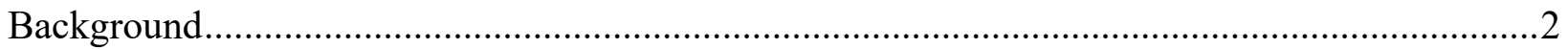

Statement of the Problem .................................................................................................

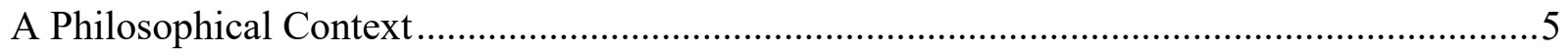

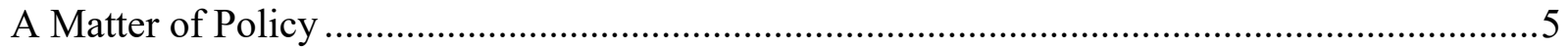

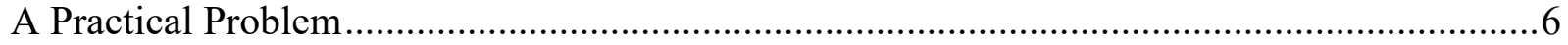

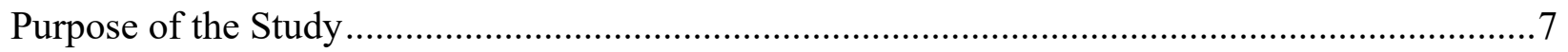

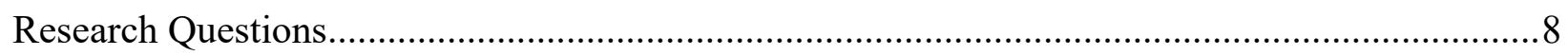

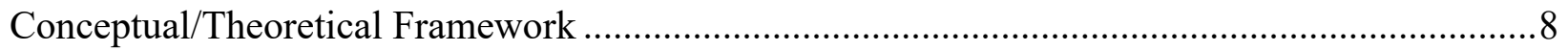

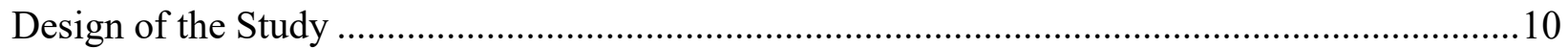

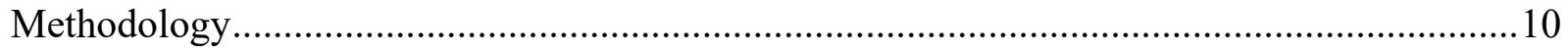

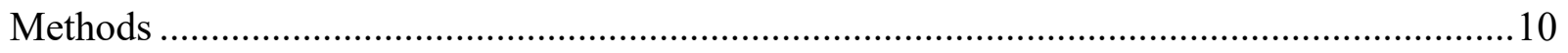

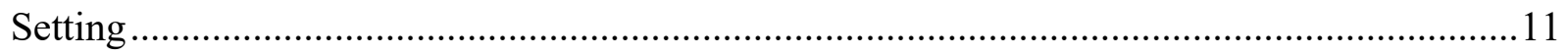

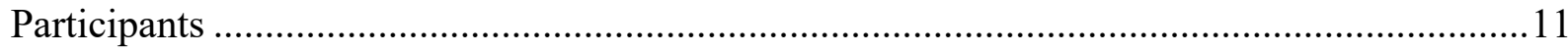

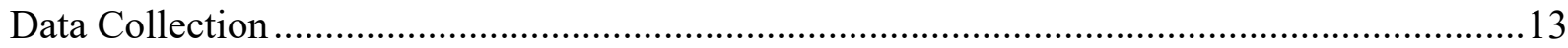

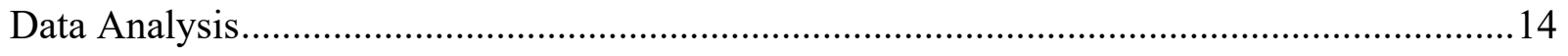




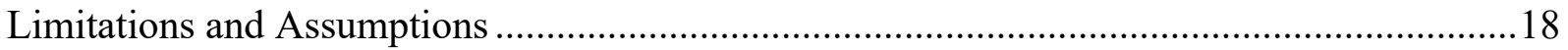

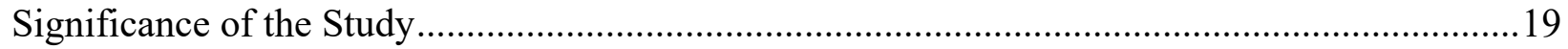

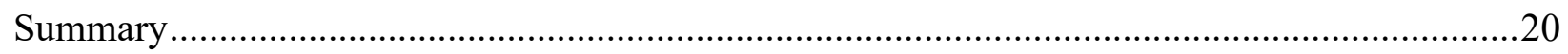

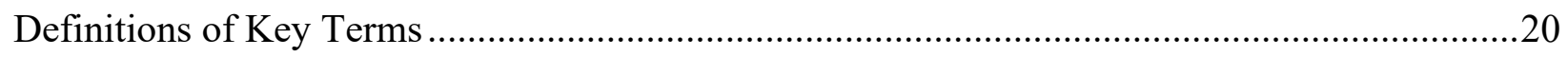

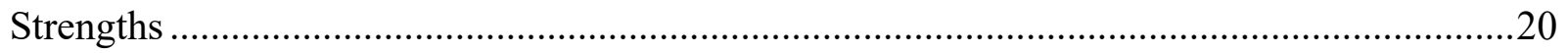

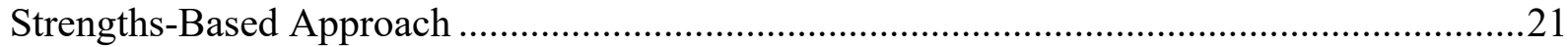

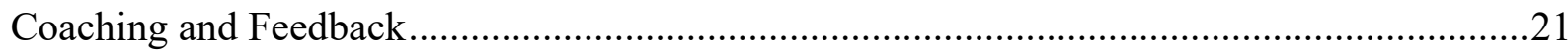

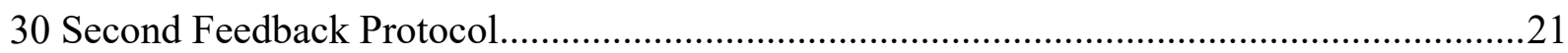

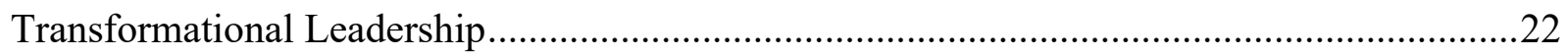

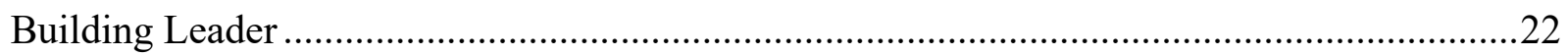

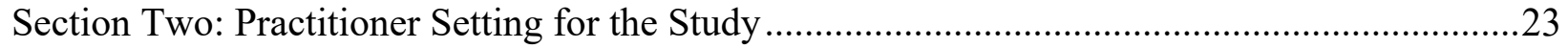

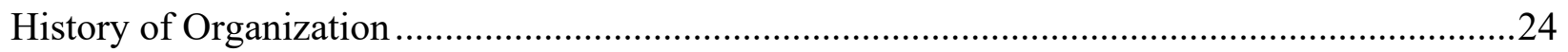

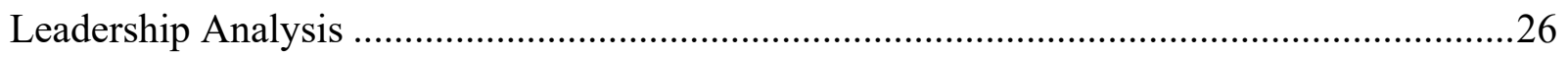

CliftonStrengths and Strengths-Based Coaching Training (Gallup) ......................................27

Instructional Leader Development (RPDC/MLDS) …….....................................................2

Strengths-Based Coaching and Feedback Training Laps (Paid RPDC Consultant) …...............30

Missouri Leadership Development System Cohort...................................................................

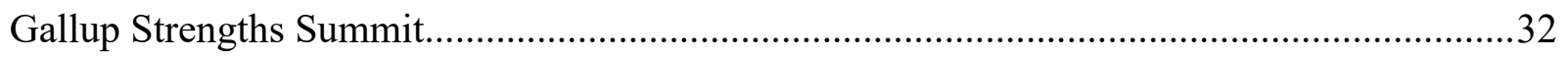

Leadership Development during COVID-19 ……………........................................................

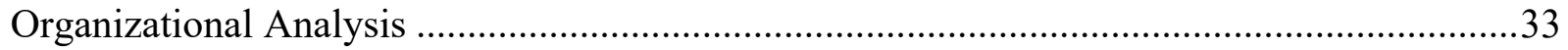


Implications and Significance for Research in the Practitioner Setting .34

Summary. .36

Section Three: Scholarly Literature Review .37

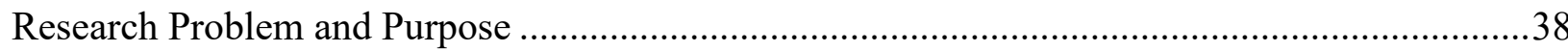

Conceptual/Theoretical Framework 39

Constructivist Epistemology. 39

Positive Psychology....... .41

Positive Psychology and Strengths Movement

Positive Psychology in the Workplace 42

Criticism of Positive Psychology 43

Literature Review and Knowledge Gaps .44

Principals as Transformational Instructional Leaders

Evolution of Teacher Evaluation 45

Teacher Observation and Feedback 46

Strengths-Based Coaching and Feedback.

Summary

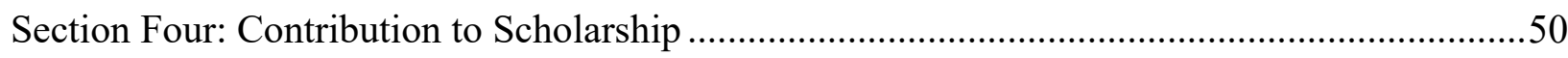

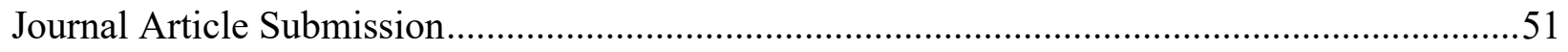

Building Leaders' Experiences with Strengths-Based Coaching and Feedback ........................51

Abstract. 
Keywords

Introduction

Theoretical Framework.

Philosophy and Policy of Instructional Leadership......

Theory of Positive Psychology.

Literature Review

Positive Psychology and Strengths Movement

Positive Psychology in the Workplace..... .58

Criticism of Positive Psychology

Principals as Transformational Instructional Leaders

Evolution of Teacher Evaluation .60

Teacher Observation and Feedback. .60

Strengths-Based Coaching and Feedback.

Research Design

Data Collection

Data Analysis.

Overview of Findings

Theme One: Visibility and Credibility as Instructional Leaders.

Theme Two: Freedom, Flexibility, and Fidelity of Implementation 
Leaders Struggled with Face-to-Face Feedback.............................................................. 71

Personal Discipline Required for Implementation with Fidelity ........................................73

Theme Three: Strengths-based coaching and its interaction with NEE................................. 74

Theme Four: Leaders Increased Knowledge of Own Strengths and Pedagogical Skills ............76

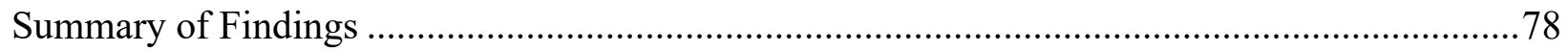

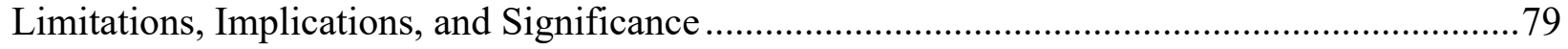

Section Five: Contribution to Practice................................................................................... 82

Growing Teachers 30 Seconds at a Time (workshop abstract) ..........................................83

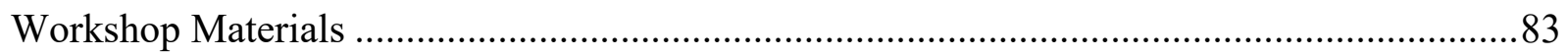

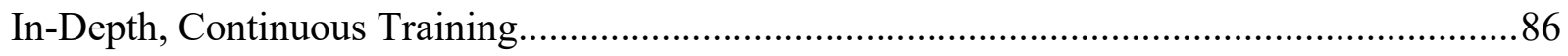

Section Six: Reflection on the Dissertation Process......................................................... 88

Dissertation Process Impact on Educational Leadership.................................................. 89

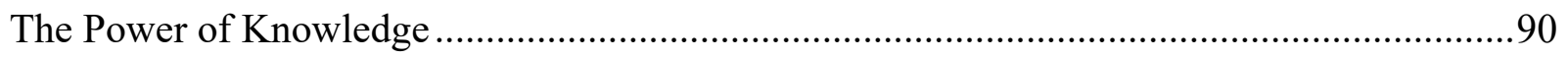

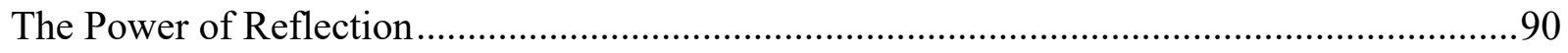

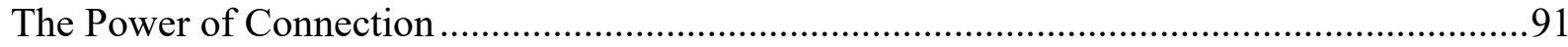

Dissertation Process Impact on Scholarship................................................................... 91

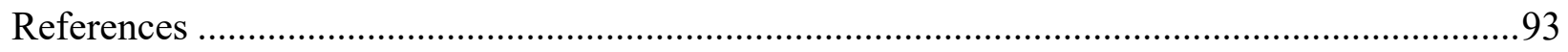

Appendix A: Semi-Structured Interview Prompts........................................................... 104

Appendix B: Strengths-Based Coaching Observation Protocol ............................................ 105

VITA 


\section{LIST OF TABLES AND FIGURES}

Table $\quad$ Page

1 Participant Demographic Information and Training Experiences.....................24

1 Participant Demographic Information and Training Experiences.....................76

2 Average Length of Feedback during Strengths-Based Field Observation.................82

Figure $\quad$ Page

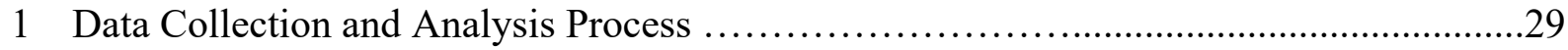

2 Participant Trainings and Learning Outcomes.................................. 39

3 Rutherford Logic Model for Instructional Leadership.............................41

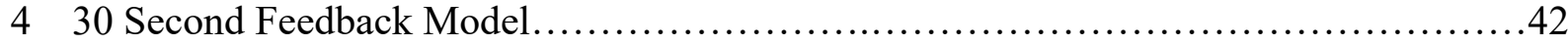

5 Summary of Themes....................................................... 91 


\begin{abstract}
This study examined the experiences of building leaders as they implemented strengthsbased coaching and feedback, exploring the overarching research question: how do building leaders implement strengths-based coaching and feedback as part of teacher development and evaluation? This qualitative case study involved four assistant principals and three head principals who were each in charge of observing and coaching teachers in one mid-sized, rural district in central Missouri. Participants were trained in positive psychology and strengths-based coaching by the Gallup organization, and in specific strengths-based coaching and feedback protocols through the Regional Professional Development Center/ Missouri Leadership Development System workshops and on-site coaching labs. Following a constructivist framework, this study examined building leaders' experiences and perspectives implementing strengths-based coaching and feedback, specifically the 30-second feedback model, as part of teacher development and evaluation. The researcher gathered data in a series of three interviews with each participant and a half-day observation of their implementation of the 30 -second feedback protocol. The study found four themes: leaders value strengths-based coaching because it increases their visibility and credibility as instructional leaders; leaders implement strengths-based coaching models with freedom, flexibility, and individual style; implementation interacts in both positive and negative ways with formal district evaluation models; and leaders' implementation of strengths-based coaching models has resulted in increased knowledge of pedagogical skills and his or her own leadership strengths. Besides being a very powerful reflection and learning experience for the participants of this case study, the results have implications for future research on the application of instructional leadership in practice. Additionally, the findings imply that further research needs to be done on the impact of
\end{abstract}


strengths-based coaching and feedback which could indicate needed policy changes in the implementation of formal evaluation models. 
Section One: Introduction to the Dissertation-in-Practice 


\section{Background}

In July of 2014, I left the classroom and entered the principalship as a high school assistant principal. One of my first assignments was to attend a two-day-long training on our district's recently adopted teacher evaluation system. Accountability policies for teacher evaluation at the state level in response to the No Child Left Behind Act of 2002 and more recent iterations of similar educational legislation led to hundreds of Missouri administrators attending training like this one (Fritzberg, 2004). I spent the day learning about the Network for Educator Effectiveness (NEE) and the 34 criteria that make a "good" teacher. By the end of this two-day training, I was certified to conduct classroom observations, score teachers objectively on the criteria, and lead meaningful post-observation conversations. This evaluation system would help me guide teachers in their development and growth.

It seemed as simple as following the prescribed method outlined by my expert instructors and founded in the educational research of Hattie (2008) and Marzano (2007). Armed with this new learning and a great desire to be an effective instructional leader, I approached my first year in administration with unbridled enthusiasm. I followed the evaluation method I had learned, clocking hundreds of hours of teacher evaluations. However, after four years of working with teachers in this evaluation model, I began to question whether or not my efforts had led to any actual improvement in the quality of teaching for those I lead.

I disliked that many of the coaching conversations I was having with teachers focused on their "number" (their NEE score). NEE evaluators are trained to score teachers between 1 and 7 on various indicators, but the rubrics are written so that earning a 7 is nearly impossible - every teacher has weaknesses; therefore, no teacher should earn a perfect score. Like their students, teachers struggled with the idea that they could not receive full credit on their evaluation. They 
were increasingly focused on any potential weaknesses and continuously looked for ways to "game" the system or argue up their score, but rarely did our conversations result in a change in teacher behavior.

Additionally, I could see our staff (myself included) developing tunnel vision around our chosen indicators. When I entered a room, I was laser-focused on just a few teaching strategies that improve student learning, and I could see teachers begin to lean into these few things while neglecting other essential strategies and skills that were not evaluated daily. Good teaching comes in a variety of shapes, sizes, and strategies, but our evaluation system was unintentionally pushing teachers away from the natural talents and skills toward a prescribed "best" way of teaching for all.

Fortunately, during this time of professional philosophical crisis, the public school district where I work as high school principal was beginning to invest in developing a strengthsbased culture in collaboration with consultation from Gallup and using the framework of CliftonStrengths (Hodges \& Clifton, 2004; Rath, 2007; Clifton \& Hodges, 2003; Winseman, 2002). The world of positive psychology and strengths-based coaching appeared at just the right time when I was ready and willing to explore new and research-based ways to be a more effective instructional leader. Whereas the evaluation system we were using was laser-focused on objectively identifying teacher improvement needs on a few particular indicators, strengthsbased coaching relies on leveraging individual talent to improve performance and manage those weaknesses so they do not hinder success. A strengths-based approach recognizes that every individual is unique in their skillset and motivations, and celebrates that success—in this case ensuring a high level of student learning — can be achieved in a variety of ways (Hodges \& Clifton, 2004). 
In turn, I developed this research to explore how principals can engage in effective instructional leadership with all of their other essential duties and amidst competing philosophies about how to grow and evaluate teachers. My research interests were born out of personal experience navigating my first year as head principal. I struggled to find my identity as a leader where I desperately wanted to coach each adult on my team in their strengths, but often fell back into the familiar "find and fix the weakness" mentality, and repeatedly got distracted by all the other administrative tasks that seemed to have nothing to do with developing either teachers or students. This research aimed to study how administrators in their roles as instructional leaders employed strengths-based coaching and feedback to sustain this type of instructional coaching throughout the year while completing other critical administrative tasks and issues in their contexts.

\section{Statement of the Problem}

This research ultimately sought to address a problem of practice. However, it is also important to understand both the philosophical and political issues that underpin this practical problem. Philosophically, instructional leadership is a vital role for building principals, but it often ignores a strengths-based approach in favor of one in which the principal identifies instructional weaknesses and provides training for teachers on how to overcome them (Hallinger, 2003). From a policy standpoint, federal and state accountability requirements and the accepted evaluation models, such as NEE and the model published by the Missouri Department of Elementary and Secondary Education (DESE), are framed in a needs-based format. In practice, the demands on principals' time make implementing strengths-based coaching and feedback challenging. 


\section{A Philosophical Context}

Teaching quality is the most significant indicator that impacts student learning in the classroom (Hattie, 2008; Marzano, 2007), followed closely by the impact of effective leadership on student success (The Wallace Foundation, 2010). So, it comes as no surprise that instructional leadership is a core competency for both national and state school leadership standards (Department of Elementary and Secondary Education [DESE], 2018; National Policy Board for Educational Administration [NPBEA], 2015). Although these standards are general, a philosophical divide is beginning to take Missouri leadership training in a different direction than other states that have adopted the Common Core Professional Standards for Educational Leaders. National Standard 6 (NPBEA, 2015) states that leaders should provide training to improve teachers' skills and knowledge. However, Missouri has added specificity to their Model Leader Standards both in the importance of timely, meaningful, and specific feedback, and the necessity of giving feedback not just on teacher weaknesses but also with a particular emphasis on growing strengths (DESE, 2018).

\section{A Matter of Policy}

Teacher evaluation systems in the United States have raised the stakes for leaders and teachers to increase student achievement and show teacher growth in other measurable ways (Ovando \& Ramirez, 2007). While some districts have embraced a lead-teacher, instructional coaching model, the building principal is ultimately responsible for teacher growth and development (Nidus \& Sadder, 2011; Ovando \& Ramirez, 2007). While the Missouri Leadership Development System (2016) has embraced a strengths-based coaching and feedback approach, state policy dictates that teacher evaluation must focus on a need for growth. "The primary purpose of the Teacher Evaluation Protocol is to promote growth. Therefore, the 
acquisition and application of new learning and skills are essential for turning opportunities for growth into outcomes and results" (DESE, 2018). NEE describes itself as a growth model focused on meaningful feedback (Network for Educator Effectiveness, 2019). Still, leaders are trained to focus almost exclusively on growth in teachers' lowest-scoring areas using a specific evaluation tool and only on a small set of predetermined criteria. Additionally, a study on the effectiveness of the NEE classroom observation rubric tools found that the feedback was not consistent in a significant percentage of classrooms and therefore lacked validity (Wind, Tsai, Grajeda, \& Bergin, 2017).

\section{A Practical Problem}

There is a growing number of demands on principals' time, and many find it increasingly difficult to engage in any instructional leadership activities. One study found that principals spend little more than 10 percent of their school day engaged in observation and feedback activities, despite research that emphasizes the importance of these activities to teacher growth (Calabrese \& Zepeda, 1999); they found: "Principals are filled with cognitive dissonance. That is, they know what theorists tell them to do; yet, the demands of the job require them to spend precious moments doing other things" (p. 7). This problem of theory versus practice is a constant battle faced by administrators who want to be instructional leaders but know that management of the school is also an important task that cannot be neglected.

As if principals' professional lives were not complicated enough, the worldwide COVID19 crisis of 2020 put an end to pretty much all well-laid plans for instructional leaders. Through a nationwide school closure, abrupt pivot to online learning, and effort to meet the immediate needs of struggling students and their families, the focus was more on surviving than strengths. However, the global pandemic also provided a new opportunity to study this specific type of 
teacher evaluation in the context of a monumental shift in public education. As schools grapple with the loss of two months of their school year due to state-mandated quarantines, and make plans to better educate students through future crises, it is crucial that teacher growth models also adapt to this agile learning environment. School leaders must be clear in their philosophy of teacher development, advocate for policies that allow for best practice in teacher evaluation, and put into practice coaching and feedback systems that improve teaching and learning in any environment.

\section{Purpose of the Study}

The purpose of this study was first and foremost to better understand how instructional leaders practically engage in strengths-based coaching and feedback within the flow of their daily work. Evaluation of teachers and providing professional development to improve teaching quality are required duties for building-level administrators. At times though, head principals, especially, are burdened with several other daily management tasks that take away from their roles as instructional leaders (Horng, Klasik, \& Loeb, 2009). There is a knowledge gap in the research on the practical implementation and experiences of those leaders and teachers who participate in strengths-based coaching and feedback, and how leaders navigate teacher development amidst daily and worldwide crises of all proportions. It is important to understand just how exactly strengths-based coaching is implemented into principals' daily duties so that future principals can fully implement a strengths-based culture and measure its impact on adult learning.

More specifically, this study uncovered common beliefs and behaviors demonstrated by leaders implementing strengths-based coaching and feedback as a part of their daily instructional leadership. The study paid special attention to how leaders implemented this relatively new 
teacher-growth model with competing demands on their time. By making sense of shared participant experiences, additional research is warranted to determine the positive impact of strengths-based coaching and feedback on teacher growth, instructional leadership, and building culture. This research is meant to push the conversation forward about how to most effectively increase teacher performance with the end goal of improving student learning.

\section{Research Questions}

The following qualitative research question will guide this study:

1. How do building leaders implement strengths-based coaching and feedback as part of teacher development and evaluation?

a. How do their attempts complement or conflict with other policies, such as the district/state teacher evaluation model?

b. How do they fit strengths-based coaching and feedback into their daily schedule?

c. In what ways has the implementation of strengths-based coaching and feedback impacted the administrator's leadership development?

\section{Conceptual/Theoretical Framework}

This study focused on participants' experiences and sense-making, so it is most appropriate to view this research study through the lens of constructivism (Creswell, 2014). Constructivism is a theoretical framework wherein humans build meaning based on their life experiences (Berger \& Luckmann, 1967; Lincoln \& Guba, 1985). Positive psychology, a movement born out of constructivism in the 1950s, focuses on leveraging positive emotions for mental health (Pluskota, 2014). Seligman and Csikszentmihalyi (2000) found that leveraging these positive emotions can lead to positive life experiences. Education has a long history with 
constructivism, and most teachers employ the tenants of positive psychology with students even if they have never named it as such.

Clifton, who the American Psychological Association has honored as the "Father of Strengths-Based Psychology," and Harter (2003), define strengths-based development in three parts: individual talent identification, individuals' internalization of these talents and investment in their development, and the resulting changes in behavior (Clifton \& Harter, 2003; Hodges \& Clifton, 2004). Strengths-based coaching focuses on increasing employees' productivity, performance, and satisfaction (Carter \& Page, 2009).

Over the last decade, the Rutherford Learning Group has promoted strengths-based coaching and feedback as a part of instructional leadership training for Missouri principals. In “A Logic Model for Instructional Leadership" (Rutherford, 2018), leaders are directed to leverage what little time they have during the day to improve teaching quality, which is one of the most significant impacts on student learning (Hattie, 2008; Marzano, 2007). Investing in individual teachers' talents and leveraging their strengths creates a culture of risk-taking and adult learning, and improves teaching in the classroom (Rutherford, 2018). From the theoretical framework of constructivism and the positive psychology movement, modern researchers such as Marzano (2007) and Rutherford (2018) have promoted practical ways for instructional leaders to implement strengths-based coaching and feedback with their teachers. Section 3 of this dissertation further explains the conceptual framework and reviews current research on strengths-based coaching and feedback, while the following section will provide extensive detail on the design and methods of this study. 


\section{Design of the Study}

\section{Methodology}

This study was qualitative in nature. "Qualitative research is an approach for exploring and understanding the meaning of individuals or how groups ascribe to a social or human problem" (Creswell, 2014, p. 4). A qualitative approach philosophically aligns with the study's purpose in better understanding leaders' experiences and how these subjects assign meaning to their experiences as professionals engaged in strengths-based coaching and feedback. This study was also qualitative because it sought to study the microcosm of just a few leaders to gain a better understanding of these particular cases (Stake, 2010). Generalizability is not a necessary outcome of qualitative research, but this study sets the groundwork for additional research that may be quantifiable to the broader context of education and instructional leadership (Creswell, 2014).

\section{Methods}

The study was conducted as a case study. This case study most closely aligns with the characteristics defined by Merriam (1998): focusing on a particular experience (e.g., strengthsbased coaching and feedback), providing rich detail of the phenomenon, and being heuristic in nature (Yazan, 2015). The researcher conducted a heuristic inquiry by creating connections between her own experiences and analyzing and understanding the data (Merriam \& Tisdell, 2016). This case study took place in a bounded system (a single school district) and focused on collecting multiple data points across four buildings with seven leaders and their followers. Gathering multiple data points across sites and conducting thoughtful analysis led to a deeper understanding of participants' experiences and was critical in addressing the philosophical, 
practical, and policy implications of the research problem previously discussed (Ovando \& Ramirez, 2007; Patton, 1990; Merriam \& Tisdell, 2016).

\section{Setting}

The research study was set in mid-Missouri, in a mid-sized public-school district where building leaders, specifically principals and assistant principals, are responsible for evaluating and giving feedback to teachers. The researcher was not a participant in this study but was a member of the bounded system. Possible biases or impacts to the study due to the nature of the researcher's professional job duties are discussed further in limitations.

\section{Participants}

Seven purposefully-chosen school leaders (principals and assistant principals) participated in this study. The decision to study both assistant and head principals is due to the structure and division of duties in this particular district; both principals and assistant principals at Lakeland Public Schools have had the same training and are implementing this same coaching model in buildings. Both principals and assistants are responsible for formally and informally evaluating teachers. Any reference to administrators or principals throughout this dissertation should be assumed to refer to both head and assistant principal participants.

Participants were chosen based on their collective leadership training, experiences with strengths-based coaching and feedback, and their roles in the coaching and evaluation process. Purposeful sampling is useful in selecting participants in a qualitative study because it allows for a more in-depth analysis of relevant, information-rich experiences (Patton, 2015; Yin, 2014; Gentles, Charles, Ploeg, \& McKibbon, 2015). Table 1 provides a summary of the participants' demographic characteristics and training experiences. 
Table 1

Participant Demographic Information and Training Experiences

\begin{tabular}{|c|c|c|c|c|c|}
\hline $\begin{array}{l}\text { Participant } \\
\text { (pseudonym) }\end{array}$ & Age & Gender & $\begin{array}{l}\text { Years and Type } \\
\text { of Administrative } \\
\text { Experience }\end{array}$ & $\begin{array}{l}\text { District-mandated } \\
\text { Training in Strengths- } \\
\text { Based Coaching }\end{array}$ & $\begin{array}{l}\text { Additional Training in } \\
\text { Strengths-Based Coaching }\end{array}$ \\
\hline Ms. Carson & $40-50$ & $\bar{F}$ & $\begin{array}{l}20+ \\
\text { Elementary }\end{array}$ & \multirow{8}{*}{$\begin{array}{l}\text { The entire team has } \\
\text { completed the following } \\
\text { strengths-based coaching } \\
\text { training over the course } \\
\text { of three years: } \\
\text { CliftonStrengths Training } \\
\text { (Gallup) } \\
\text { Strengths Coach Training } \\
\text { (Gallup) } \\
\text { Leadership Training } \\
\text { (RPDC/MLDS) } \\
\text { Onsite Coaching Lab } \\
\text { Experience (Consultant) }\end{array}$} & MLDS Cohort \\
\hline Mr. Edgar & $30-40$ & $\mathrm{M}$ & $\begin{array}{l}5-10 \\
\text { Elementary }\end{array}$ & & $\begin{array}{l}\text { MLDS Cohort } \\
\text { Gallup Strengths Summit }\end{array}$ \\
\hline Mr. Ellis & $40-50$ & $\mathrm{M}$ & $\begin{array}{l}10-20 \\
\text { Elementary }\end{array}$ & & \\
\hline Ms. Cardwell & $30-40$ & $\mathrm{~F}$ & $\begin{array}{l}5-10 \\
\text { Secondary }\end{array}$ & & $\begin{array}{l}\text { MLDS Cohort } \\
\text { Gallup Strengths Summit }\end{array}$ \\
\hline Mr. Martin & $50-60$ & $\mathrm{M}$ & $\begin{array}{l}5-10 \\
\text { Secondary }\end{array}$ & & \\
\hline Mr. Shank & $40-50$ & $\mathrm{M}$ & $\begin{array}{l}20+ \\
\text { Secondary }\end{array}$ & & Gallup Strengths Summit \\
\hline $\begin{array}{l}\text { Ms. Johnson } \\
\text { (researcher) }\end{array}$ & $30-40$ & $\mathrm{~F}$ & $\begin{array}{l}5-10 \\
\text { Secondary }\end{array}$ & & $\begin{array}{l}\text { MLDS Cohort } \\
\text { Gallup Strengths Summit }\end{array}$ \\
\hline Mr. Lindell & $30-40$ & $\mathrm{M}$ & $\begin{array}{l}5-10 \\
\text { Secondary }\end{array}$ & & \\
\hline
\end{tabular}

These leaders have completed training in strengths-based coaching and feedback through both Gallup CliftonStrengths Coaching workshops and a consultant from the Regional Professional Development Consortium (RPDC). CliftonStrengths coaching was delivered both in-district, by a paid consultant, and through the Gallup Strengths Summit, a national convention in Omaha which some participants attended in either 2018 and 2019. Missouri Leadership Development System (MLDS) is a training and mentoring program for Missouri principals in their first seven years of the principalship. Now in its third cohort, MLDS is working with over 1,000 principals statewide through monthly workshops on leadership, coaching labs in which participants practice their learning in real-school settings, and mentoring partnerships to help grow transformational leaders. Four of these eight participants have been formally trained 
through the MLDS program; all eight participants have had an MLDS trainer provide in-district training specifically on strengths-based coaching and feedback (which is just one element of the entire MLDS curriculum).

\section{Data Collection}

Data collection took place in the natural setting (building leaders' schools) and included multiple data sources (Creswell, 2014). First, each leader participated in a series of semistructured interviews that sought to understand both the structure and nature of strengths-based coaching as it fits into building leaders' daily workflow. The researcher used a transcription application to record and transcript each interview. She intentionally refrained from taking notes during the interview process to encourage open and honest dialogue through the use of active listening skills. A protocol was developed based on Seidman's model of in-depth phenomenological interviewing (Seidman, 2006). (See Appendix A.) The first interview allowed the leader to explain their journey toward building leadership and their identity as a strengthsbased coach. The second interview focused on the structure of strengths-based coaching and feedback within the daily workflow of participants. These questions allowed the researcher to look for trends in the "what" of teacher observation and feedback (frequency, length, type, among other elements). After the field observation of participants implementing 30-second feedback, a final interview dug deeper into the nature of strengths-based coaching and feedback, looked to answer "how" and "why" questions, and allowed the leader and researcher to make sense of their experiences. This semi-structured interview style met Creswell's (2014) emergent design criteria; it was not tightly prescribed, so that the researcher had the flexibility to adapt the research process based on the emerging data from all participants. Each interview included 1-2 
structured questions, allowing for additional open-ended, follow-up questions and clarifying statements to flow from the dialogue between researcher and participant.

The researcher observed participants through a half-day of observation and feedback to collect data between the second and third interviews. Because the timing of this study took place during the worldwide COVID-19 pandemic, it is relevant to note that this school district was in session with face-to-face instruction for all students. Social distancing and a mask mandate for employees were in place during data collection, but the study was completed as planned in a typical learning environment. The researcher took the stance of observer-as-participant, meaning that while the researcher could interact with participants, those interactions were secondary to the researcher's role as observer (Merriam \& Tisdell, 2016). An observational protocol included collecting both objective observational data and the researcher's reflections and impressions of the data (Bogden \& Biklen, 1992; Creswell, 2016) (see Appendix B). This observational protocol included objective data on the physical setting, participants, activities and interactions, conversation (both verbal and nonverbal, clear and subtle), and the observer's subjective feelings and interpretations of the observed data. The researcher chose not to audio or visually record the observations in order to avoid collecting data from teachers or students, who were not the subjects of the research study.

\section{Data Analysis}

In case studies, attention to data management is of vital importance to the study's success. As is the preferred method in qualitative research, data analysis coincided with data collection (Merriam \& Tisdall, 2016). The researcher analyzed each data set before moving on to the next step of data collection. So, every participant participated in the first interview within the same week. After the first round of interviews, the researcher listened to each recording (in the same 
order the interviews were conducted) and took note of main points, themes, and significant statements. The researcher created a chart where responses were color-coded by participant and sorted according to their relevance in answering each part of the research question. Common themes were connected with arrows and paraphrased at the bottom of each column. This process was repeated after each round of interviews. The researcher continued connecting main ideas to form a list of emergent themes from the 14 paraphrased ideas, combined into eight topics, and finally distilled to four significant findings.

This process was organized using Stake's (2010) assembly plan model so that both significant themes, which appeared in several pieces of data, and patches, which were meaningful pieces of learning that only appeared in a few pieces of data, are both represented in the data analysis of emergent themes. In qualitative research, "reliability and validity are conceptualized as trustworthiness, rigor, and quality" (Golafshani, 2003, p. 604). To accomplish this, the researcher returned to the full data set (the chart from each round of interviews) and compared each statement to the emergent themes, and coded each statement with a number (coordinating to the summarized common theme), an asterisk (meaning the information did not connect to a common theme but represented a significant patch in the researchers' mind) or a hyphen (meaning the statement did not relate to an emerging theme and also was not a significant patch in the data set).

This study ensured triangulation, defined as "a validity procedure where researchers search for convergence among multiple and different sources of information to form themes or categories in a study" (Creswell \& Miller, 2000, p. 126). Besides conducting three interviews per participant (21 total interviews), the researcher also analyzed data from observation field notes. The analysis was grouped in the same way the data was collected. At both elementary 
buildings and one secondary building, the administrators walked around as a pair and took turns implementing the 30-second feedback model. The analysis occurred after the observations and looked at the pair of participants as one data set (the seventh participant at the other secondary building was included in the data set with the other secondary administrators). The observations took place between the second and third interviews but were the last set of data coded. The data was marked using the number/asterisk/hyphen coding described above. The field observation was also coded $(\mathrm{S}=$ strengths, $\mathrm{P}=$ =edagogy) to represent principal identification of instructional strategies and references to the use of specific strengths vocabulary. Finally, after distilling the information down to four main findings, the researcher revisited the detailed raw data (audio recording/transcript of interviews, field notes, and data charts) through the lens of the results to ensure validity and accuracy. Figure 1 is a visual representation of the data analysis process. 


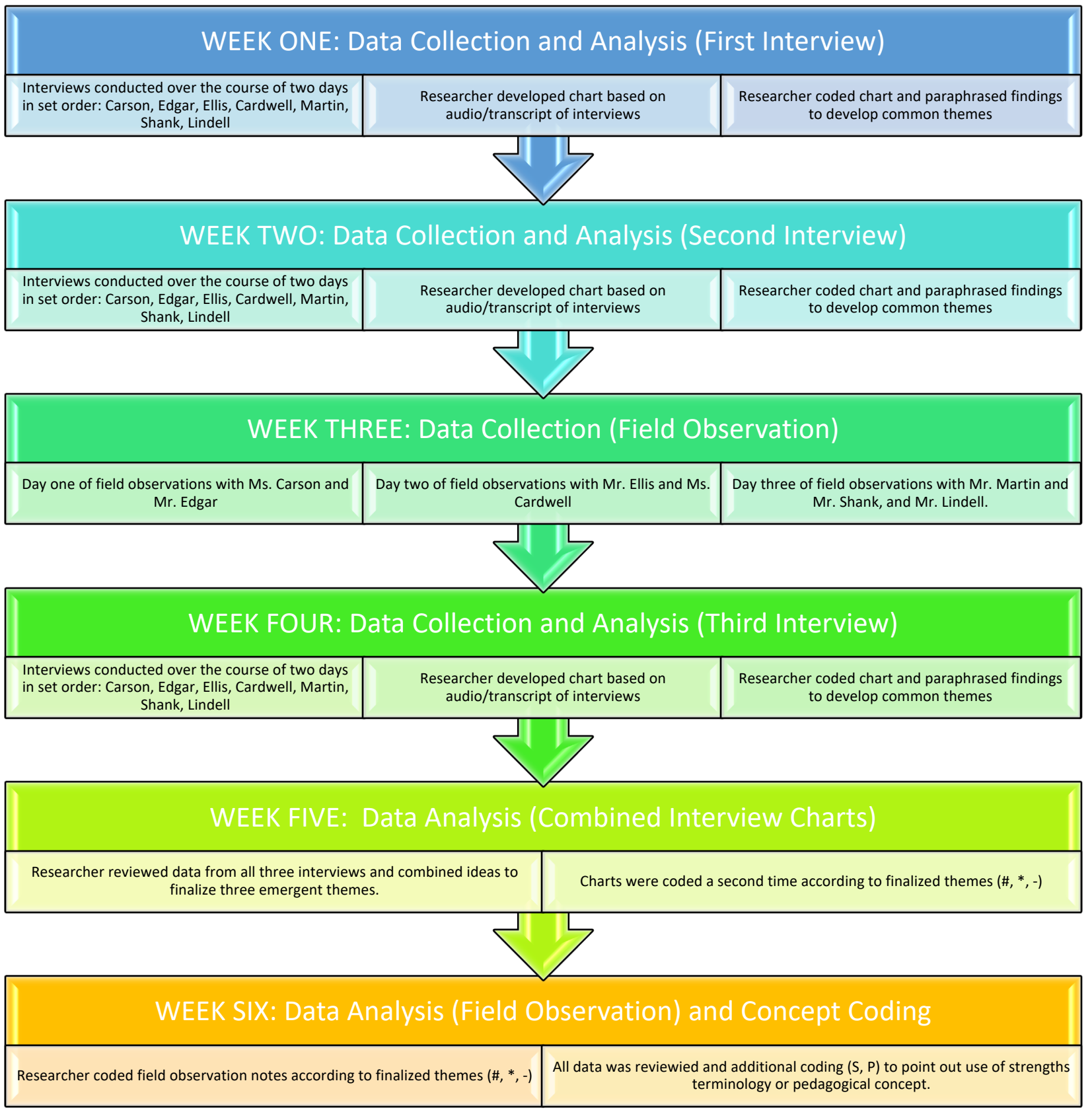

Figure 1: Data Collection and Analysis Process. This model summarizes the steps in the data collection and analysis process including the order in which interviews and observations took place, how data was analyzed, and the types of analysis that were completed. 


\section{Limitations and Assumptions}

Participants were purposefully chosen due to their homogenous philosophy on instructional leadership and their roles in this specific bounded system. One significant assumption of this study is that it did not explore the intersection of strengths-based coaching and feedback in the daily lives of all types of building leaders, limiting itself only to this group of like-trained leaders in this particular, unique context. A second possible limitation regards my role as both researcher and colleague to the participants in the study. The research was understood through the lens of my own experiences and preconceived notions with strengthsbased coaching and feedback. Also, being a colleague to the participants may have made it more difficult for participants to share their negative perceptions, failures, or obstacles for fear of seeming incompetent. To mitigate this limitation, we had an upfront and honest conversation before the first interview to both revisit the purpose of the study, the confidentiality of the process, and my openness to set aside any personal bias with the goal of discovering themes based solely on the participants experiences separate of my own. Additionally, this possible limitation turned to somewhat of an advantage as the credibility and trust already developed between researcher and participant led to open, honest, and in-depth data collection during the interview and observation process. Section two provides more detail about my role in the study context.

The most critical assumption of this study is that the participants used their knowledge gained about strengths-based coaching and feedback through the MLDS and employed it according to that training. This study was not focused on measuring the implementation of a specific coaching model or feedback protocol. It instead assumed that these leaders are all using strengths-based coaching in some form and that the focus is on how it was implemented by each 
participant rather than whether it was being implemented "correctly" according to a specific prescribed model. Additionally, it is assumed that instructional leadership and development are a primary responsibility of every building leader that should be incorporated into their daily work. Finally, this study was purposely structured as qualitative and heuristic in nature; it is assumed that the study's purpose was to build knowledge and theory, not to generalize or replicate across the educational leadership context as a whole.

\section{Significance of the Study}

This study is significant, in the most selfish of senses, because it has helped me as a school leader to better engage in strengths-based coaching and feedback at my institution. Suppose I did nothing more than discover and document at least a few key ideas from experienced leaders in how to practically implement a strengths-based culture. That alone would significantly impact me as a leader and those teachers whom I coach daily. Beyond the personal, this research study addressed the practical, political, and philosophical implications of the research problem.

This study is significant because it took the growing research in strengths-based coaching and feedback and presented the practical experiences of people working in the field. By reporting on the experiences of both leaders and teachers who are focused on strengths-based coaching and feedback, the educational community at large can explore the possible implications of developing a strengths-based culture in schools across the nation. Positive experiences shared among participants involved in this study warrant further research into the possible benefits of transitioning from a needs-based to a strengths-based evaluation model. Further research should explore whether strengths-based models grow teachers more effectively and lead to an overall improvement in teaching quality and student learning. 
If strengths-based evaluation gains momentum in practice, it begs the question as to why policy still preferences needs-based evaluation models and whether legislators should reform policy based on the body of research supporting strengths-based development. This study has the potential to take what we know about instructional leadership, feedback, and professional development from the realm of the theoretical into the practical, allowing for school leaders to engage in practices that move their buildings forward.

\section{Summary}

This research study was born from the researcher's desire to use her role as a leader to transform teachers to reach their maximum potential with regards to classroom instruction. The issue at hand is a conflict between coaching models that focus on teacher deficit and those that strive to leverage teacher strengths for increased performance. This philosophical divide is also noticeable in Missouri's inconsistent policies. The approved leadership development system advocates for a focus on strengths, but required evaluation models are still tied to teacher deficit and growth plans meant to address weaknesses. Even more problematic, instructional leaders face the most practical problem of implementing strengths-based coaching and feedback into their work as duties and demands of the job are ever-increasing. By examining how individual talent and strengths can be leveraged to improve performance, this dissertation adds to the existing literature on the topic of strengths-based coaching and feedback.

\section{Definitions of Key Terms}

\section{Strengths}

For this study, it should be noted that the term "strengths" refers to "an individual's ability to consistently provide near-perfect performance" in a specific activity and that strengths derive from knowledge, skills, but most importantly from one's talents, which are innate qualities 
(Hodges \& Clifton, 2004; Clifton \& Harter, 2003). This definition of strengths is synonymous with what other researchers have called core qualities, competencies, or essential aspects (Ofman, 2000; Korthagen, 2002).

\section{Strengths-Based Approach}

The strengths-based approach emphasizes the impact of focusing on individual talent as a way to maximize performance. Researchers in the field of positive psychology describe the strengths-based approach as a three-step process. First, individuals must identify their unique talents. After identification, individuals internalize and invest in developing those talents into strengths. When individuals identify and internalize their strengths, they feel more satisfied and fulfilled (Park \& Peterson, 2008). This internalization leads to the third phase, changes to individual behavior (Clifton \& Harter, 2003; Hodges \& Clifton, 2004).

\section{Coaching and Feedback}

Feedback as part of a coaching model is information provided to an individual or group that is timely, specific, growth-evoking, ongoing, and authentic (DESE, 2018).

\section{Second Feedback Protocol}

This feedback model delivers short, strengths-based reinforcement from observer to classroom teacher. Observers start with an introductory sentence, then point out a specific moment, strategy, or example of exemplary teaching. Observers then tie a particular effect of learning (an impact on student learning) due to the teacher's work before encouraging the teacher to continue leaning into their strengths. The feedback is always positive and informal in nature (Rutherford Learning Group). 


\section{Transformational Leadership}

Transformational leaders engage with and empower followers, acting as both an encourager and challenger to individuals and the organization (Northouse, 2016; Rooke \& Torbert, 2005). Transformational leadership occurs when the leader develops a shared vision and inspires followers to grow in their own craft to help meet that vision.

\section{Building Leader}

For this research study, the participants are often referred to as building leaders and represent both principals and assistant principals responsible for the coaching and evaluation of teachers in the district. The terms building leader, administrator, or principal are used interchangeably in this dissertation to refer to all participants. In the literature review, careful consideration was given to the use of leadership terms to most accurately represent the meaning of the cited sources. 
Section Two: Practitioner Setting for the Study 
My experiences in my current district inspired this study analyzing strengths-based coaching and feedback. Initially, I was interested in seeing how other leaders across the state had implemented strengths-based coaching and feedback in their various contexts. However, I quickly realized that the context I was working in was incredibly unique. Lakeland Public Schools (a pseudonym) is the only district in Missouri that has invested in strengths-based philosophy through a partnership with CliftonStrengths for the entire staff and student population, and the administrative team has had years of specific training in strengths-based coaching with Gallup, RPDC/MLDS, and paid consultants. I began to understand that I would not be able to find similar contexts to do a comparative study. Therefore, I embraced the opportunity to do a case study on my own district and how leaders implemented strengths-based coaching and feedback in their daily work.

\section{History of Organization}

Lakeland Public Schools is a mid-sized rural district located on the shores of Lake of the Ozarks, a regional tourist destination in mid-Missouri. The district was founded in 1933 to educate children of laborers working to build the Bagnell Dam. Today, Lakeland Public Schools educates approximately 2,000 students in PK-12 grades and employs around 250 staff members, making it one of the largest employers in the lake area. While racial/ethnic diversity in the district is lacking, students come from various socio-economic backgrounds. Million-dollar lake homes, resorts, and boat marinas dot the shoreline, but over half of students live below the poverty line while their parents strive to make ends meet on seasonal work. The district itself is financially healthy, maintaining one of the lowest property taxes in the state while providing state-of-the-art facilities and resources to students. In the past decade, the community passed both 22 and 23 million dollar bond initiatives to renovate Leland Elementary (housed in the 
original 1933 building) and Lakeland High School. The bonds paid for cutting-edge fine arts and technology classrooms at the high school, updated security to all campus buildings, a district field house, and an early childhood center dedicated to providing universal preschool to all threeyear-olds in need.

Over the last seven years, Lakeland has had a fierce commitment to continuous growth. It has invested heavily in strategic planning (through both Baldridge and Studer organizations) and staff development to meet students' needs in the $21^{\text {st }}$ century. Lakeland Public Schools' mission is to partner with students, families, and the community to equip all learners to meet their maximum potential for a lifetime of success. Teachers and administrators begin every meeting by saying this mission aloud and connecting it to their work and purpose. The district's core values are Tradition, Strengths, Opportunity, and Innovation. Each of these core values is evident in the strategic plan that has pushed Lakeland forward. Lakeland Public Schools is steeped in tradition. Many students and staff members have multigenerational ties to the district; the community is highly involved and supportive. For the last five years, Lakeland has made a considerable investment (both financially, in training and implementation) in a strengths-based philosophy of teaching and learning. Teachers and students are trained through a partnership with Gallup to name, claim, and aim their unique strengths and leverage them for success. Administrators have worked with several consultants and trainers to implement strengths-based coaching and feedback with teachers.

A focus of the last two five-year strategic plans has also been on increasing opportunities for both staff and students. The district invests a large percentage of resources in staff salaries and extra duty stipends (first in the central region of Missouri and reaching to compete with St. Louis and Kansas City suburban pay). Students are continually provided with the same 
opportunities (advanced coursework, remediation programs, athletic and fine arts programming) found in much larger districts across the state. From an innovation standpoint, Lakeland Public Schools has embraced virtual learning and technology systems for the last several years.

Currently, all staff members receive technology integration training into instructional practices and have 1:1 technology resources for use in the classroom. Students in grades K-12 are 1:1 iPads, and the district is in the fourth year of integration of Canvas as a virtual learning management system. Curriculum and professional development opportunities are focused on integrating new teaching and learning methods to meet the needs of today's students and prepare them for careers that may not currently exist.

In the spring of 2020, the COVID-19 pandemic changed our world, and schools across the nation were impacted by mass school-closures and the need to shift to an entirely virtual learning model within days. Lakeland Public Schools was able to successfully transition to virtual learning in less than one week. Lakeland returned to seated courses in the fall of 2020 , with systems in place to pivot to virtual or blended models due to school closure or student quarantines. This study took place in the fall/winter of 2020-2021; the school remained open for face-to-face instruction for all students throughout the school year.

\section{Leadership Analysis}

Lakeland Public Schools operates under the leadership of one head and one deputy superintendent, and each building has both a head and assistant administrator who are responsible for teacher coaching and evaluation. These eight building-level administrators range in experience from 5 to 25 years. Because the district had a strong focus on leadership development, all of these eight leaders have participated in the following training: CliftonStrengths (Gallup Consultant), Strengths-Based Coaching (Gallup Consultant), 
Instructional Leader Development (Regional Professional Development Consortium), StrengthsBased Coaching and Feedback (Missouri Leadership Development System consultant), and OnSite Coaching Lab (MLDS Consultant). Figure 2 summarizes the shared training and background knowledge of the participants.

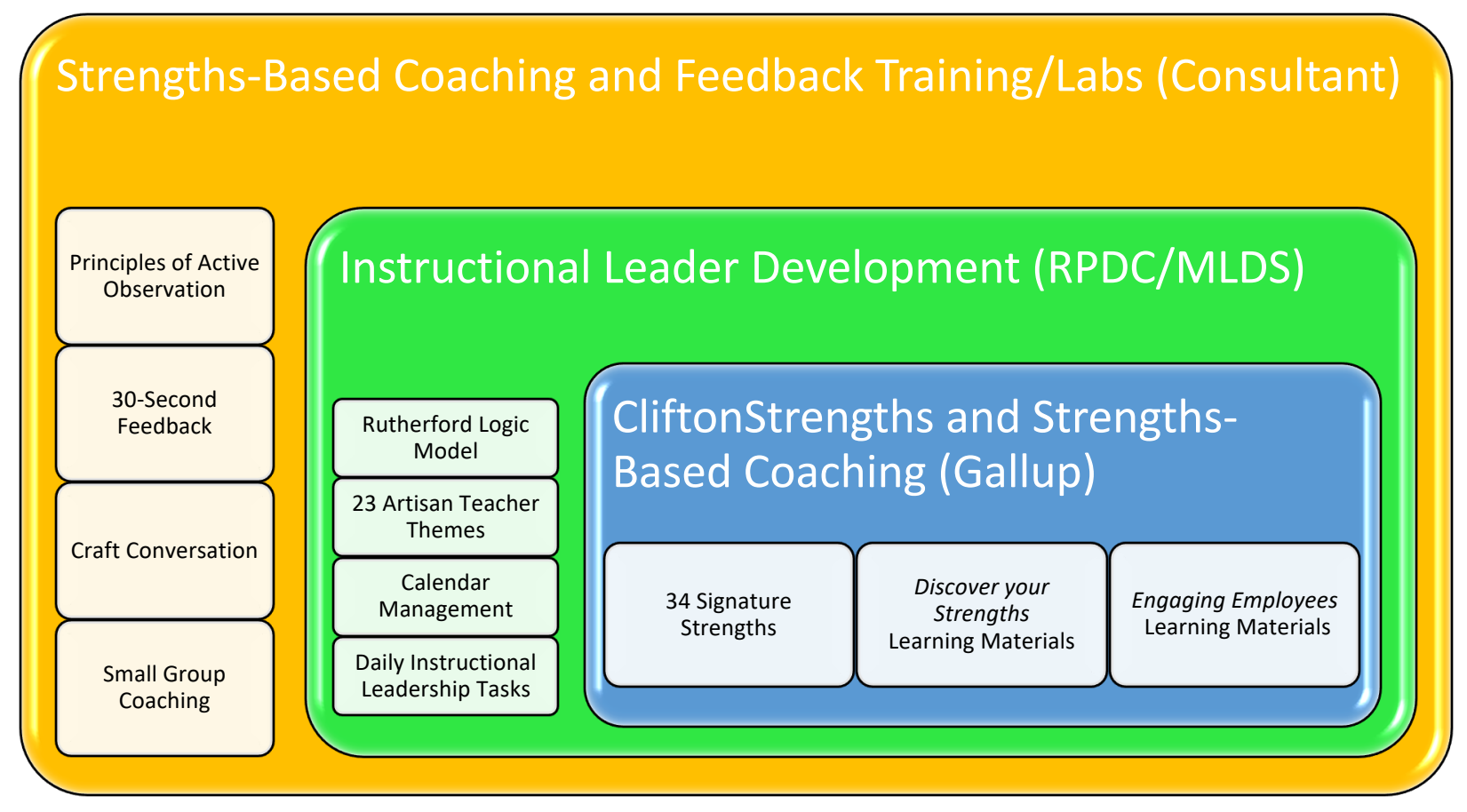

Figure 2: Participant Trainings and Learning Outcomes. The research participants have a common understanding and background in strengths-based instructional leadership due to three main trainings. Within each training are common learning themes/outcomes which were used by participants during the study.

\section{CliftonStrengths and Strengths-Based Coaching Training (Gallup)}

Gallup, Inc., who facilitated CliftonStrengths and Strengths-Based Coaching Training, describes itself as a "global analytic and advice firm that helps leaders and organizations solve their most pressing problems" (Gallup, Inc. 2020). Their core values include focusing on talent, developing world-class managers, focusing on mission-driven work, and helping organizations grow and develop their employees. CliftonStrengths is the analytical tool that drives strengths- 
based training programs delivered by consultants to organizations like Lakeland Public Schools. Over the last three years, administrators have participated in an initial two-day leadership retreat and annual one-day training (five days total leading up to the time of this study) delivered on-site by a paid consultant. In these workshops, leaders worked through the Discovering Your Strengths workbook to name, claim, and aim their own strengths, and through the Engaging Employees materials to understand how to leverage employees' strengths to maximize performance and satisfaction. These interactive pieces of training challenged administrators to understand and plan for implementation of the CliftonStrengths coaching tools into their instructional leadership duties. Next, administrators took part in training to implement strengths philosophy into practice.

\section{Instructional Leader Development (RPDC/MLDS)}

In coordination with the Heart of Missouri RPDC, the district brought in two consultants for a day-long workshop to develop building administrators' instructional leadership skills based on the Rutherford Logic Model of instructional leadership. The Rutherford Logic Model for Instructional Leadership (Figure 3) reflects both the role of principal as transformational instructional leader and the philosophy of strengths-based coaching as a foundation for teacher growth. 


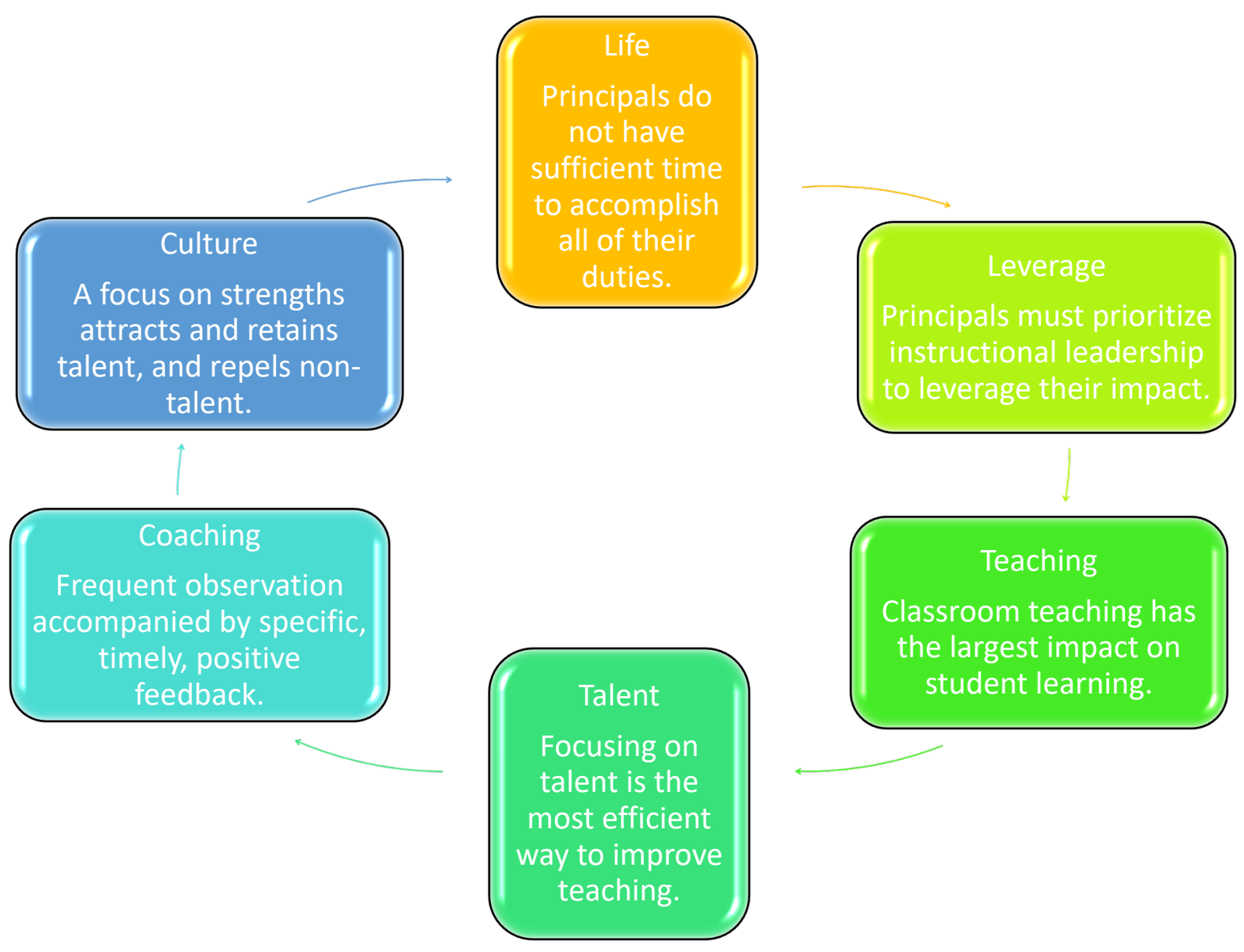

Figure 3: Rutherford Logic Model for Instructional Leadership. This model promotes instructional leadership as the most prioritized duty for principals and strengths-based coaching and feedback as the best use of principals' time to improve teaching, learning, and culture in their buildings. Adapted from Rutherford (2018).

The objective of this training was to frame building leaders' role as the primary instructional leader and lead learner of his or her building. It also focused on helping each leader build a plan for managing their calendars to include a focus on instructional leadership and implementation of the building improvement plan (focusing on teacher and student 
performance). The two trainers are also responsible for the MLDS regional cohort, and this training incorporated elements of the MLDS training offered in the first two sessions of the cohort. This successful training led one of the trainers to become a multi-year paid consultant for the specific strengths-focused training that followed.

\section{Strengths-Based Coaching and Feedback Training Laps (Paid RPDC Consultant)}

During the 18-19, 19-20 (until March school closure), and 20-21(year of this study) school years, the district contracted a paid consultant to come in four to six times per year to train building leaders on specific strengths-based coaching strategy and protocols, including principles of active observation, the 30 -second feedback model (Figure 4), craft conversation, and small group coaching.
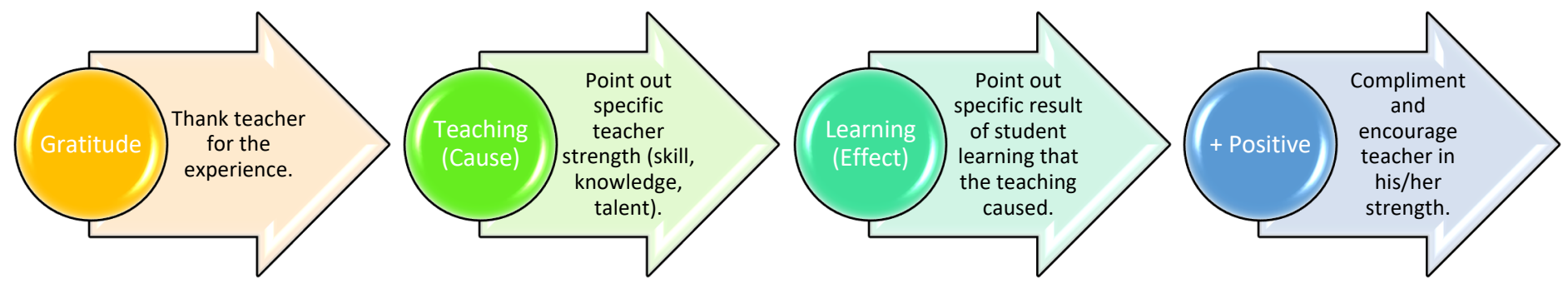

Figure 4: 30 Second feedback model. After a brief statement of thanks, the principal points out one specific teaching strength and the impact on student learning, before ending the conversation by encouraging the teacher to continue to use strengths. Adapted from Emerging Level Participant Guide (Missouri Leadership Development System (2016) and Rutherford (2018).

The first half (1-3 hours) of each training included instruction or reinforcement of strengthsbased coaching approaches. The second half (1-3 hours) of the training was a coaching lab experience where leaders observed and practiced strengths-based coaching and then received feedback from the consultant and other lab participants. 
All research study participants and the researcher attended all training provided in-district by Gallup, RPDC/MLDS, and the paid consultant. It is important to note that these various training pieces all stem from the foundation of positive psychology and the strengths movement (further explained in the literature review), but that they differ in the specific frameworks, vocabulary, and protocols they employ. For example, CliftonStrengths includes 34 signature talent themes and works to engage employees and coaches in leveraging and developing these strengths. Strengths-based coaching provided by RPDC/MLDS is founded in the Rutherford Learning Group framework for strengths-based coaching protocols and in The Artisan Teacher (Rutherford, 2013), which identifies 23 themes of effective instruction and instructors. Many administrators took advantage of additional voluntary training described below (review Table 1 for a summary of which participant completed each training.

\section{Missouri Leadership Development System Cohort}

In addition to those shared training experiences, various building leaders at Lakeland Public Schools completed additional, voluntary strengths-based training in the last five years. The Missouri Leadership Development System (MLDS) is a training program for Missouri principals funded through the Missouri Department of Elementary and Secondary Education (DESE) and aligned to the Professional Standards for Educational Leaders (Missouri Leadership Development System, 2016; National Policy Board for Educational Administration, 2016). This system serves over 4,000 Missouri principals by providing training and coaching labs. The curriculum for the MLDS program is based on the work of Rutherford (2018) and founded in the research of Hattie (2008) and Marzano (2007). Each cohort of leaders develops skills to move through four levels of leadership: aspiring, emerging, developing, and transformational. Ms. Carson, Mr. Edgar, and Ms. Cardwell are part of the same MLDS cohort and, as of the time of 
data collection, were three years into their training and in the emerging level of instructional leadership. Principals in the emerging phase of the MLDS program are trained to use the Rutherford Model of Instructional Leadership to engage in strengths-based coaching and feedback using the 7 Principles of Active Observation protocol (Rutherford, 2018; MLDS) and 30-second feedback model, among others. Administrators participated in coaching labs in districts across the region to practice active observation and strengths-based feedback. Investing in individual teachers' talents and leveraging their strengths creates a culture of risk-taking and adult learning, and improves teaching in the classroom (Rutherford, 2018).

\section{Gallup Strengths Summit}

Every summer, Gallup hosts a Strengths Summit at its headquarters in Omaha for thousands of leaders who utilize CliftonStrengths in their organizations. The summit is a gathering place for professionals to connect and share best practices; attendees come from all types of organizations, from small businesses to educational institutions to Fortune 500 companies. Mr. Edgar, Ms. Cardwell, and Mr. Shank, and the researcher attended the Gallup Strengths Summit in person in 2018 and 2019; they went to several breakout sessions over two days that focused on various topics, including strengths-based coaching and feedback. In 2020 the Gallup Strengths Summit was held virtually due to COVID-19, and all building leaders were registered and given access. It is unclear how many webinars the administrators attended or the level of their interaction with the material, so Table 1 does not include attendance at the 2020 Strengths Summit. It is essential to understand the collective training and experiences which preceded this study and impacted the findings. In this particular case, all participants had a shared understanding of positive psychology, strengths-based coaching, strengths terminology, and specific protocols used when working with teachers. 


\section{Leadership Development during COVID-19}

Before the COVID-19 pandemic, the district was firmly on the path of embracing a positive strengths-based philosophy and coaching with students, families, and staff members. Resources and time have been invested into the development of building leaders to work with teachers from a strengths-based, as opposed to a needs-based perspective. During school closure from March-May of 2020, it would make sense that many of these standard processes, including how leaders were coaching teachers, would be completely disrupted. On the one hand, this absolutely happened; classroom observations ceased, and conversations about individual talents and signature strengths were few and far between. On the other hand, school closure provided a great learning opportunity for leaders to find new and innovative ways to engage with teachers, to observe and evaluate teachers in a unique learning context, and to lean into strengths that may have gone unnoticed in the traditional classroom. The leadership team reported an increased focus on the relationship between leader and follower, engaging the pair in increasing motivation, morality, and performance of both (Northouse, 2016); this focus on positive psychology despite immense disruption to the educational environment, allowed leaders to exhibit transformational skills focused on helping followers realize their full potential (Bass \& Avolio, 1990).

\section{Organizational Analysis}

At Lakeland Public Schools, recruiting and retaining high-quality staff is a top priority for district leadership (Lakeland Public Schools, 2018). To that end, the district has invested substantial time and money into developing instructional leaders, as described in the previous section. This organization is best understood through Bolman and Deal's (2013) human resource frame, wherein "people's skills, attitudes, energy, and commitment are vital resources that can 
make or break an enterprise" (p. 117). This mental model for understanding the research environment helps explain why so much emphasis is placed on classroom teachers' development. From the roots of positive psychology and as an extension of Maslow's Hierarchy of Needs, McGregor (1960) proposed that human beings desire to develop—physically, socially, emotionally, intellectually_ and organizations who strive to inspire and satisfy their employees are more likely to align individual and organizational goals to reach greater success. McGregor's Theory Y (Bolman \& Deal, 2013) is at work in Lakeland Public Schools, as demonstrated by classroom teachers who want to improve and be good at their jobs and building administrators who are implementing coaching systems that align with and support this goal. In the introduction to the literature review, positive psychology and the strengths-based movement define the philosophy at work in this organization. Another critical component of the human resource frame is that healthy organizations have a clear philosophy and systems that support the organizational vision. "A philosophy provides direction; practices make it operational" (Bolman \& Deal, p. 141).

\section{Implications and Significance for Research in the Practitioner Setting}

This study has several implications for both researcher and participants. First, this study provides a chance for each building leader to reflect on their own practice and learn from others' experiences in a way that is mostly impossible during the school year. All of these participants have attended training in strengths-based feedback. They have even been lucky enough to participate in a lab experience where they practiced applying their skills. Still, none of them have had the opportunity for deep reflection and analysis of their training in practice. As a building principal in this district, responsible for the development of 45 teachers and over 600 students 
each year, I am incredibly invested in this research and its implications on my own professional development.

Second, the research has implications for transformational instructional leadership in practice. Although this qualitative case study centered around the perspectives of a particular group of leaders with a shared (but unique in the general context of education) strengths-based training and approach to coaching, it has important implications for instructional leadership across contexts. As discussed in the literature review, transformational instructional leadership is a heavily researched topic. Researchers have described the ideal transformational leader as one who cares for their employees' development (Turner, Barling, \& Zacharatos, 2002), empowers others (Hallinger, 1992), and is a leader of leaders (Brandt, 1992). And yet, Calabrese \& Zepeda (1999) found that despite the extant literature on the benefits of the principal as instructional leader, in practice, principals are unable to put theory into practice amidst all the other requirements of their daily work. The analysis and results of strengths-based coaching and feedback provide for practical ways to move principals closer to the ideal definition of instructional leader and implies that it is possible for leaders to capture one of the most critical tenants of instructional leadership: empowering others to reach their maximum potential (Northouse, 2016).

Third, the study has implications for the use of formal teacher evaluation models such as the NEE. A central theme of the study revolves around the intersection of strengths-based coaching and feedback and NEE and finds that there are both positive and negative impacts to the formal evaluation model. Further studies should examine how to incorporate strengths-based coaching as part of a formal evaluation process that maximizes teacher performance and preserves the validity and accuracy of formal tools. It should also analyze whether strengths- 
based coaching has a more significant impact on teacher performance and self-efficacy than current formal evaluation tools - in this case, results could cause sweeping policy reform to evaluation models across public education.

\section{Summary}

The context of this study is unique. Few studies center on strengths-based coaching and feedback and fewer still analyze how this model is practically implemented within principals' daily workflow. The intersection of positive psychology and practical implementation makes this district an excellent setting for this study. These implications are significant both at a micro level, wherein the individual participants and researcher are developing their craft as they make sense of the research experience, and the macro level, where the findings have implications for both the practical implementation of instructional leadership and for possible policy/systematic changes that would improve formal evaluation practices. 
Section Three: Scholarly Literature Review 
Principals play many roles: manager, mediator, financial officer, investigator, public relations supervisor, to name a few. Of utmost importance, however, is their role as instructional leaders. This qualitative case study helped building leaders make sense of how they work with teachers to improve teaching and learning in the classroom. More specifically, this study followed a selected group of instructional leaders as they employed a strengths-based coaching and feedback model. Strengths-based coaching is a manifestation of the positive psychology movement and is a relatively novel concept in schools where needs-based methods of evaluation and accountability have been the norm for decades. This introduction offers a brief overview of the research problem and purpose and an in-depth explanation of the constructivist framework and the positive psychology concepts that guided the study. Furthermore, the literature review introduction provides a background to transformational instructional leadership, teacher evaluation, and the research base for exploring the employment and impact of a strengths-based coaching model in school.

\section{Research Problem and Purpose}

This research addressed a problem of practice, policy, and philosophy. Building principals are responsible for the management of their buildings and the learning of both adults and the children they serve. However, studies continue to show that building leaders find it challenging to focus on instructional leadership amidst all the other demands of the job (Calabrese \& Zepeda, 1999; Horng, Klasik, \& Loeb, 2009). Instructional leadership has increasingly become a required skill for principals, although novice principals receive little training or development in this area (Hvidston, Range, McKim, \& Mette, 2015). This represents a philosophical paradigm shift in leadership, from one that values management skills to frameworks such as transformational leadership that focus on a leader's ability to empower his or 
her followers to grow professionally (Hallinger, 1992). Additionally, emerging research supports the use of strengths-based coaching and feedback as an effective way to improve employee performance. (Van Woerkom \& Meyers, 2015; Aguinis, Gottfredson, \& Joo, 2012). However, current educational policy requiring needs-based evaluations has not improved teacher quality (Toch \& Rothman, 2008).

The purpose of this research study was to address the practical, philosophical, and political implications of instructional leadership founded in strengths-based coaching and feedback. The researcher conducted a qualitative, multi-case study to better understand how building leaders engage in strengths-based coaching and feedback within their daily workflow. By first understanding strengths-based coaching and feedback in practice, this study also uncovered emergent themes that support a philosophical shift from needs-based growth models. Moreover, this study adds to the body of research that supports policy reform at both the state and national levels.

\section{Conceptual/Theoretical Framework}

\section{Constructivist Epistemology}

Constructivism is an epistemological perspective that upholds that new knowledge and learning occur as beings engage with and interpret particular experiences (Ültinar, 2012). Constructivists posit that individuals strive to order their worlds and develop their own "personal realities” (Mahoney, 2002, p. 747), and as Boghossian (2006) explains, “Each person's

subjective experience is just as valid as anyone else's, and no one has an epistemically privileged viewpoint" (p. 714). That is not to say that constructivists believe all truth is relative. Roots of constructivism can be tied back to philosophers like Immanuel Kant. He believed that absolute Truth exists separate of the human condition and that individuals may come to form different 
meanings about life and truth based on their own experiences (Mahoney, 2002). Constructivism as an epistemology has framed research in psychology, sociology, philosophy, and education (Ültinar, 2012; Bada, 2015).

John Dewey, John Piaget, Lev Vygotsky, Jerome Bruner, and Howard Gardner have each contributed significantly to the understanding of constructivism in the context of educational psychology (Fosnot \& Perry, 2005). John Dewey, a founder of the progressive education movement, brought constructivism into the world of education by reasoning that students can learn best through experience (Dewey, 1938). His later works clarify that even though education requires experience, experience is not necessarily educational, citing the importance of teachers who facilitate age-appropriate and developmentally meaningful experiences to initiate student learning (Dewey, 1998; Fensham, Gunstone \& White, 2012). John Piaget, a biologist and cognitive constructivist, began to differentiate between the learning of children and adults, focusing primarily on children and how their cognitive development caused them to rationalize and perceive learning in new and more abstract ways (Ültinar, 2012). Lev Vygotsky agreed with Piaget but made a distinction in the learning of spontaneous and scientific concepts (Fosnot \& Perry, 2005). He defined the Zone of Proximal Development as the time and space in which a learner is appropriately challenged by the new material but has enough background knowledge to scaffold the new concept into existing knowledge (Vygotsky, 1986).

Constructivism is an appropriate epistemological approach to this research study for several reasons. First, the study itself is constructivist as it makes sense of each subject's learning through their own experiences. Second, the theoretical framework of positive psychology is closely linked to the constructivist worldview; "A large part of [positive psychology and constructivism's] promise may therefore stem from their openness to a more 
holistic conceptualization of what it means to be human and to be partially and developmentally conscious" (Mahoney, 2002, p. 750).

\section{Positive Psychology}

Seligman is largely considered to be the 21 st-century pioneer in the field of positive psychology (Pluskota, 2014; Myers, 2000), although he clarifies in several of his writings that positive psychology is not a new field or even a paradigm shift but instead a returning to a part of the original mission of psychology, which is to better understand how to improve the lives of all people (Seligman \& Csikszentmihalyi, 2000). By the middle of the twentieth century, psychology had become primarily focused on studying pathology and treating or curing mental illness (Pluskota, 2014). Seligman and Csikszentmihalyi (2000) hoped to usher in a renewed interest in the study of fulfillment, happiness, joy, productivity, and perseverance. Positive psychologists are studying ways to leverage human beings' talents and abilities to both prevent mental illness and improve the quality of life (Seligman, 2002). In more layperson terms, Clifton,

founder of CliftonStrengths and Gallup, Inc. and proponent of positive psychology, asks, "What would happen if we studied what was right with people versus what is wrong with people?" (Buckingham \& Clifton, 2001).

\section{Positive Psychology and Strengths Movement}

Positive psychology promotes that each person has the potential for growth based on their talents and character strengths (Pluskota, 2014). "Psychology is not just the study of disease, weakness, and damage; it also is the study of strength and virtue" (Seligman, 2002). Clifton spearheaded strengths research at the University of Nebraska (Hodges \& Harter, 2005). Clifton and Harter (2003) explain strengths-based development as a three-step process. First, individuals identify their individual and unique talent themes. The Clifton StrengthsFinder is one such 
diagnostic tool based on 30 years of research meant to identify unique themes of talent in individuals. After identification, individuals internalize and invest in developing those talents into strengths. When individuals identify and internalize their strengths, they feel more satisfied and fulfilled (Park \& Peterson, 2008). This internalization leads to the third phase, changes to individual behavior (Clifton \& Harter, 2003; Hodges \& Clifton, 2004).

\section{Positive Psychology in the Workplace}

Employees who have higher levels of autonomy, challenging work, social interaction, choice, and competency are more satisfied and engaged in their work (Turner, Barling, \& Zacharatos, 2002; Carter \& Page, 2009). Additionally, recent studies in corporate and educational settings have shown positive outcomes, including increased productivity and employee engagement (Hodges \& Clifton, 2004). Managers who employ positive psychology and strengths-based approaches double the likelihood of success for themselves and their organizations (Clifton \& Harter, 2003).

There are multiple strengths-based models of change; Appreciative Inquiry (AI) is one such model that "seeks to appreciate strengths" through five interdependent principles: the positive, constructionist, simultaneity, anticipatory, and the poetic (Cooperrider \& Srivasta, 2017). AI "encourages organizations to identify strengths and imagine possibilities to outgrow problems and realize visions" (Tschannen-Moran \& Tschannen-Moran,2011, p. 422). AI is based upon eight foundational assumptions that connect to both constructivism and positive psychology. Five of these assumptions deal specifically with how organizations and the people within them create reality based on their individual perceptions and experiences. Two additional assumptions state that 1) every person has unique talents that should be valued, and every organization does something that works; and 2) discussing and exploring these positive aspects 
and each other's realities influences both individuals and the organization (Walker \& CarrStewart, 2004; Elleven, 2007).

The AI organizational change model and strengths-based workplace movements are similar in that they believe the foundation for improvement is a focus on leveraging individual talent and organizational strengths to improve individual and organizational performance. Drs. Tschannen-Moran (2011) found that AI applied to educational settings creates an environment where innovation, risk-taking, and learning can occur. Growth and development occur when people can identify, value, and mobilize their strengths (Fenton, Walsh, Wong, \& Cumming, 2014).

\section{Criticism of Positive Psychology}

Exponents of positive psychology have two main criticisms of its foundational premises: first, psychologists point out that it is difficult, perhaps even negligible, to focus on positive features of the human experience separate from negative traits (Guignon, 2002). It is those negative features that also make us human (Martin, 2006). Second, Miller (2008) argues that positive psychology employs circular reasoning that reduces the human experience to a list of positive attributes required to live a good life and negative attributes that should be avoided. "Both optimism and pessimism, so far as they have descriptive or explanatory value, must surely be counted as traits or features of a healthy, mature, balanced outlook" (p. 599). These critics point to the importance of employing a scientific method and analytical wariness to the study of positivity, happiness, and fulfillment in order to resist the urge to devolve into the realm of selfhelp pseudoscience. 


\section{Literature Review and Knowledge Gaps}

In preparing to study how building leaders engage in strengths-based coaching and feedback within the context of their daily work, it is essential to first explore the evolution of instructional leadership and teacher evaluation systems in public education. Then, this review will briefly touch on best practice research surrounding classroom observations and feedback. Finally, the review will present a model of strengths-based coaching and feedback being employed by the subjects of this qualitative multi-case study.

Grounded in positive psychology and strengths-based philosophy, this study focuses on the practical implementation of strengths-based coaching by building administrators. School leadership has become a crucial part of leadership research in recent decades. The literature review will analyze the existing literature on instructional leadership frameworks such as transformational, servant, and authentic leadership, and the evolution of teacher evaluation and strengths-based coaching and feedback.

\section{Principals as Transformational Instructional Leaders}

The principal's evolving role from an authoritative manager to transformational leader closely mirrors the rise and fall of popular leadership models of the last century. Trait theory, dominant through the mid-1940s, proposed that leaders inherently possess specific traits that predispose them to successful leadership (Northouse, 2016). Later studies redefined and challenged traditional trait theory and argued that situational factors are also crucial in classifying leaders as effective (Stogdill, 1948; Mann, 1959; Lord, DeVader \& Alliger, 1986). Regardless of the variances in thought regarding the traits leaders may or may not need to bring to their positions, modern educational researchers widely agree that instructional leadership is a vital role of the building leader (Nidus \& Sadder, 2011; Wallace Foundation, 2010; Ovando \& 
Ramirez, 2007; Neumereski, 2012; O’Donnell \& White, 2005). As expectations for principals have evolved to place an increased emphasis on instructional leadership, models such as transformational, servant, and authentic leadership have become the focus of much educational research (Hallinger, 2003; Beck, 2014; Collins, 2011; George, Sims, McLean, \& Mayer, 2011).

Transformational leadership requires that the leader engages with and empowers followers, acting as both an encourager and challenger to individuals and the organization (Northouse, 2016; Rooke \& Torbert, 2005). Transformational leaders contribute to the satisfaction and growth of their followers (Turner, Barling, \& Zacharatos, 2002); they "care for the work-related development of their employees" (p. 721). In contrast to simply being instructional leaders who act as the singular experts in curriculum and instruction, the term "transformational instructional leader" is more accurate in describing principals who empower their teachers to be the instructional experts (Hallinger, 1992). As Sergiovanni noted, "Principals ought to be leaders of leaders: people who develop the instructional leadership in their teachers" (Brandt, 1992, p. 48). The subjects of this study have all been trained in transformational instructional leadership skills. Their training exposes them to strengths-based coaching and positive psychology as a means to improve teaching.

\section{Evolution of Teacher Evaluation}

Teacher evaluation systems are the primary way of measuring teacher effectiveness in the classroom (Weisberg, Sexton, Mulhern, \& Keeling, 2009). The ways in which principals currently evaluate teachers have their roots in the scientific management movement that accompanied the industrial revolution (Marzano, Frontier, \& Livingston, 2011). If schools were like factories, then it followed that the factory workers (teachers) could be given a specific set of 
instructions, and they could all be measured by the same standard according to the quality of the product (students) they produced.

After World War II, Cogan (1973) and Goldhammer (1969) promoted a clinical method of evaluation that, in some ways, resembles systems of evaluation that are currently in place. It is important to note, though, that their work intended to take a holistic approach to the observation of teaching, the interaction between teacher and student, and its impact on student learning (Marzano, Frontier, \& Livingston, 2011). Despite its original intent, the holistic model was reduced to teacher evaluation wherein supervisors looked for specific and predictable lesson structure, activities, and outcomes, and ignored the most critical variable in student learning, the individual teacher (Marzano, Frontier, \& Livingston, 2011).

Several recent reports have critiqued current evaluation systems. Toch and Rothman (2008) claim that current systems of evaluation are more concerned with credentials than learning. Other authors explain how clinical evaluation practices have resulted in the assumption that all classrooms, and the teachers who run them, should look and act the same and produce the same results (Weisberg, Sexton, Mulhern, \& Keeling, 2009). "In its denial of individual strengths and weaknesses, [current practice] is deeply disrespectful to teachers; in its indifference to instructional effectiveness, it gambles with the lives of students" (p. 34). Current observation models focus on deficiency instead of strengths, and teachers' and principals' voices have been largely absent in designing evaluation systems (Ovando \& Ramirez, 2007).

\section{Teacher Observation and Feedback}

Teacher observation is an authentic and essential activity in teacher evaluation systems (Zepeda, 2006). Former qualitative studies have found that both principals and teachers value walk-through observations and feedback as one of the most accurate ways to show what is really 
happening in the classroom (Ovando \& Ramirez, 2007; Ovando, 2001). Teacher observation can have a positive impact on both teacher growth and student performance. "Data showed that students of teachers observed more frequently collectively had greater gains in the performance of their students than those who had fewer observations" (Shaha, Glassett \& Copas, 2015). Some research has shown that observations that are informal, unannounced, short, and frequent throughout the year are most impactful to teacher growth and student learning (Marshall, 2005; Marshall, 2012).

Feedback is a crucial component of observation and essential for maximizing employee engagement and growth (Turner, Barling, \& Zacharatos, 2002). Frequent and specific feedback is necessary for a comprehensive evaluation program (Weisberg, Sexton, Mulhern, \& Keeling, 2009). However, in a study of over 15,000 teachers, nearly 74 percent reported that they received no specific feedback about their craft, and over half did not agree that evaluation improves teacher performance (Weisberg, Sexton, Mulhern, \& Keeling, 2009). This suggests that additional methods and approaches are necessary, such as strengths-based coaching.

\section{Strengths-Based Coaching and Feedback}

Teacher observation accompanied by feedback is an important and necessary part of teacher evaluation programs (Anast-May, Penick, Schroyer \& Howell, 2011). However, in recent years, more research has focused explicitly on the benefits of strengths-based coaching and feedback. For this study, it should be noted that the term "strengths" refers to "an individual's ability to consistently provide near-perfect performance" in a specific activity, and that strengths derive from knowledge, skills, but most importantly from one's talents, which are innate qualities (Hodges \& Clifton, 2004; Clifton \& Harter, 2003). This definition of strengths is synonymous with what other researchers have called core qualities, competencies, or essential 
aspects (Ofman, 2000; Korthagen, 2002). So, when a principal is giving strengths-based feedback, they are particularly pointing out a teacher's applied talents, knowledge, and skills to leverage those positive traits to higher performance levels.

In a quantitative study, Hiemstra and Van Yperen (2015) found that subjects who engaged in strengths-based identification and professional development activities to build on these strengths scored significantly higher than those who focused on trying to improve their deficits in several areas: perceived competence, intrinsic motivation, and effort. In a more largescale study, Van Woerkom and Myers (2015) found that employees who received strengthsbased feedback rated their work-related satisfaction and performance significantly higher than those who did not work in strengths-based organizations. "To fully reap the benefits of using feedback, managers should instead primarily rely on a strengths-based approach to feedback that consists of identifying employees' areas of positive behavior and results that stem from their knowledge, skills, or talents" (Aguinis, Gottfredson, \& Joo, 2012, p. 106).

Feedback after observations should be specific, timely, and note teachers' strengths and positive teaching strategies (Marshall, 2012; Whitaker, 1997; Anast-May, Penick, Schroyer \& Howell, 2011). One effective way to structure feedback is by tying a specific teacher strength to a specific outcome of student learning as a cause-and-effect conversation (Aguinis, Gottfredson, \& Joo, 2012). This type of specific feedback inspires teacher self-reflection that results in improved teaching and learning in the classroom (Marzano, Frontier, \& Livingston, 2011). In summation, the literature is clear-principals ought to be transformational instructional leaders who engage in frequent, formative, and positive observation and feedback cycles with their teachers (Grissom, Egalite, \& Lindsay, 2021). 


\section{Summary}

By employing a constructivist worldview and theoretical framework of positive psychology, this review has outlined the research base for the application of strengths to the field of educational leadership. The principal's role has evolved to favor transformational instructional leadership styles and made teacher evaluation a central duty for building-level administrators. Teacher observation and feedback are an essential part of evaluation, and research promotes that strengths-based coaching and feedback can positively impact teaching and learning in the classroom. In this qualitative case study, the researcher observed building principals as they conduct frequent and consistent observations followed by specific, timely, and positive feedback focused on strengths. The purpose of this research is to make sense of how leaders engage in this important activity within the context of their other duties as principals and to identify emergent themes in how strengths-based coaching and feedback impacts both leaders and teachers. 
Section Four: Contribution to Scholarship 


\title{
Journal Article Submission
}

For the contribution to scholarship, my goal is to compile this research into a journal article that meets the criteria for Educational Administration Quarterly (EAQ). EAQ reaches a worldwide audience of educational leaders and focuses on significant school leadership topics that directly target practicing building and district-level administrators. I believe this study is of interest to leaders who want to be transformational, who are looking for ways to develop and grow their followers in the art and science of teaching. EAQ publishes many qualitative case studies each year that explore teacher evaluation and growth models in diverse contexts. This journal has become a powerful learning tool in my own life because it has opened the door to educational contexts outside the United States. The most recent publications look at educational issues in Israel, Asia, and the United States. What I have found most interesting is that despite the vast differences in these educational systems, instructional leadership and the implementation of best practices can look similar across contexts. I am excited about the prospect of adding knowledge to the global classroom.

EAQ requires a report of research that fits within the 25-40-page limit. Additionally, EAQ submissions must meet style and grammar requirements of the $7^{\text {th }}$ edition of The Publication Manual of the American Psychological Association (APA) and must have active hyperlinks and digital object identifiers for cited sources. To preserve the style of the dissertation in practice, citations have not been hyperlinked.

\section{Building Leaders' Experiences with Strengths-Based Coaching and Feedback}

\author{
Abstract \\ Purpose: This study examined the experiences of building leaders with strengths-based \\ coaching and feedback. The primary research question was: How do building leaders implement
}


strengths-based coaching and feedback as part of teacher development and evaluation? Sub questions included: how do their attempts complement or conflict with other policies, such as the district/state teacher evaluation model; how do they fit strengths-based coaching and feedback into their daily schedule; and, in what ways has the implementation of strengths-based coaching and feedback impacted the principal's leadership development? Design: This qualitative case study involved seven participants (assistant and head principals) in one mid-sized, rural district in central Missouri who have been trained in positive psychology and strengths-based coaching, specifically the 30 -second feedback model. The researcher gathered data in a series of three interviews with each participant and a half-day observation of their implementation of 30 -second feedback protocol. Findings: The study found four themes: leaders value strengths-based coaching because it increases their visibility and credibility as instructional leaders; leaders implement strengths-based coaching models with freedom, flexibility, and individual style; implementation interacts in both positive and negative ways with formal district evaluation models; and leaders' implementation of strengths-based coaching models has resulted in increased knowledge of pedagogical skills and his or her own leadership strengths

\section{Keywords}

strengths, strengths-based approach, coaching and feedback, 30-second feedback, transformational leadership

\section{Introduction}

I entered my first year of building leadership in 2014 with unbridled enthusiasm and 12 hours of training in how to evaluate and grow teachers. Perhaps that is a simplification of my experiences; I had earned multiple degrees in educational administration and learned much from my years in the classroom that would benefit me as a principal. On the other hand, I had never 
had a "growth conversation" with a teacher or completed a formal classroom observation, so those 12 hours of training with the Network for Educator Effectiveness (NEE) facilitator would come to define my early years of instructional leadership. I followed the prescribed method I had learned, clocking hundreds of hours of teacher evaluations. However, after four years of working with teachers in this evaluation model, I began to question whether or not my efforts had led to any actual improvement in the quality of teaching for those I led.

I was unhappy that NEE required assigning teachers a number, that our staff was developing tunnel-vision around just a few indicators of instructional effectiveness instead of embracing the belief that good teaching comes in a variety of shapes, sizes, and strategies. I felt something was missing; fortunately, during this time of professional philosophical crisis, the public school in Missouri where I worked as a principal was beginning to invest in developing a strengths-based culture of teaching and learning. A strengths-based approach recognizes that every individual is unique in their skillset and motivations and celebrates that success can be achieved in various ways (Hodges \& Clifton, 2004). This approach made its way into our coaching and evaluation practices, resulting in the implementation of strengths-based coaching and feedback, most notably the 30-second feedback model developed by the Rutherford Learning Group.

This case study explored how building leaders in this medium-sized public school district in mid-Missouri engage in effective strengths-based coaching and feedback amidst all of their other essential leadership duties. The primary research question was: How do building leaders implement strengths-based coaching and feedback as part of teacher development and evaluation? Sub questions included: how do their attempts complement or conflict with other policies, such as the district/state teacher evaluation model; how do they fit strengths-based 
coaching and feedback into their daily schedule; and, in what ways has the implementation of strengths-based coaching and feedback impacted the principal's leadership development?

While philosophical and theoretical studies of effective instructional leadership abound, this specific study strove to fill the practical gap: how do building leaders, in practice, actually implement this type of coaching model? As shown in the following section, there is a knowledge gap in the research on the practical implementation and experiences of leaders and teachers who participate in strengths-based coaching and feedback, and how leaders navigate teacher development amidst daily and worldwide crises of all proportions. This study is significant because it takes the emergent research in strengths-based coaching and feedback and presents the practical experiences of people working in the field. By reporting on the experiences of building leaders who are focused on strengths-based coaching and feedback, the educational community at large can explore the possible implications of developing a strengthsbased culture in other contexts. This article begins with a review of the theoretical framework and extant literature on strengths-based coaching. Then, the research design and methods are set within the context of the case study. Finally, the article concludes with a discussion of the findings, practical applications, limitations, and future research implications.

\section{Theoretical Framework}

This research ultimately sought to address a problem of practice. However, it is also important to explore both the philosophical and political issues that underpin this practical problem, which are each shaped by various theories about instructional leadership. In short, as shown in the following sections, this research is framed by theories of instructional leadership and positive psychology. 


\section{Philosophy and Policy of Instructional Leadership}

Philosophically, instructional leadership is a vital role for building principals, especially knowing that teaching quality is the most significant indicator which impacts student learning in the classroom (Hattie, 2008; Marzano, 2007), followed closely by the impact effective leadership has on student success (The Wallace Foundation, 2010). Traditionally, the philosophical approach to teacher evaluation often ignores a strengths-based approach in favor of one in which the principal identifies instructional weaknesses and provides training for teachers on how to overcome them (Hallinger, 2003). These two philosophical approaches have shaped Missouri leadership training. Specifically, National Standard 6 (NPBEA, 2015) provides that leaders should provide training to improve teachers' skills and knowledge. Missouri has added specificity to their Model Leader Standards both in the importance of timely, meaningful, and specific feedback, and the necessity of giving feedback not just on teacher weaknesses but also with a particular emphasis on growing strengths (DESE, 2018).

From a policy standpoint, federal and state accountability requirements and the accepted evaluation models, such as NEE and the model published by the Missouri Department of Elementary and Secondary Education (DESE), are framed in a needs-based format. NEE describes itself as a growth model focused on meaningful feedback (Network for Educator Effectiveness, 2019), but leaders are trained to focus almost exclusively on growth in teachers' lowest-scoring areas using a specific evaluation tool and only on a small set of predetermined criteria. Additionally, a study on the effectiveness of the NEE classroom observation rubric tools found that feedback was not consistent in a significant percentage of classrooms and therefore lacked validity (Wind, Tsai, Grajeda, \& Bergin, 2017). 


\section{Theory of Positive Psychology}

This study focused on the experiences and sense-making of participants, so it is most appropriate to view this research study through the lens of constructivism (Creswell, 2014). Constructivism is a theoretical framework wherein humans build meaning based on their life experiences (Berger \& Luckmann, 1967; Lincoln \& Guba, 1985). Positive psychology, a movement born out of constructivism in the 1950s, focuses on leveraging positive emotions for mental health (Pluskota, 2014). Seligman and Csikszentmihalyi (2000) found that leveraging these positive emotions can lead to positive life experiences. Education has a long history with constructivism, and most teachers employ the tenants of positive psychology with students even if they have never named it as such.

Seligman is largely considered to be the 21 st-century pioneer in the field of positive psychology (Pluskota, 2014; Myers, 2000), although he clarifies in several of his writings that positive psychology is not a new field or even a paradigm shift but instead a returning to a part of the original mission of psychology, which is to better understand how to improve the lives of all people (Seligman \& Csikszentmihalyi, 2000). By the middle of the twentieth century, psychology had become primarily focused on studying pathology and treating or curing mental illness (Pluskota, 2014). Seligman and Csikszentmihalyi (2000) hoped to usher in a renewed interest in the study of fulfillment, happiness, joy, productivity, and perseverance. Positive psychologists are studying ways to leverage human beings' talents and abilities to both prevent mental illness and improve the quality of life (Seligman, 2002).

In more layperson terms, Clifton, founder of CliftonStrengths and Gallup, Inc. and proponent of positive psychology, asks, "What would happen if we studied what was right with people versus what is wrong with people?” (Buckingham \& Clifton, 2001). Clifton, who the 
American Psychological Association has honored as the "Father of Strengths-Based

Psychology," and Harter (2003), define strengths-based development in three parts: individual talent identification, individuals' internalization of these talents and investment in their development, and the resulting changes in behavior (Clifton \& Harter, 2003; Hodges \& Clifton, 2004). Strengths-based coaching focuses on increasing employees' productivity, performance, and satisfaction (Carter \& Page, 2009).

Over the last decade, the Rutherford Learning Group has promoted strengths-based coaching and feedback as a part of instructional leadership training for Missouri principals. In "A Logic Model for Instructional Leadership" (Rutherford, 2018), leaders are directed to leverage what little time they have during the day to improve teaching quality, which is one of the most significant impacts on student learning (Hattie, 2008; Marzano, 2007). Investing in individual teachers' talents and leveraging their strengths creates a culture of risk-taking and adult learning, and improves classroom teaching (Rutherford, 2018). From the theoretical framework of constructivism and the positive psychology movement, modern researchers such as Marzano (2007) and Rutherford (2018) have promoted practical ways for instructional leaders to implement strengths-based coaching and feedback with their teachers.

\section{Literature Review}

The literature review provides a background on the theory of positive psychology in practice - as the foundation for the strengths movement in the workplace, and the implications for instructional leadership. Additionally, a review of the evolution of teacher evaluation and strengths-based coaching is provided to expose the gaps in understanding. The knowledge gap flows from the fact that positive psychology and strengths philosophy have shown the ability to increase employee performance, and instructional leadership is one highly valued for leaders to 
implement this framework. However, studies have not made sense of how this is actually accomplished in practice - a gap exists where theory meets reality.

\section{Positive Psychology and Strengths Movement}

Positive psychology promotes that each person has the potential for growth based on their talents and character strengths (Pluskota, 2014). "Psychology is not just the study of disease, weakness, and damage; it also is the study of strength and virtue" (Seligman, 2002). Clifton spearheaded strengths research at the University of Nebraska (Hodges \& Harter, 2005). Clifton and Harter (2003) explain strengths-based development as a three-step process. First, individuals identify their individual and unique talent themes. The Clifton StrengthsFinder is one such diagnostic tool based on 30 years of research meant to identify unique themes of talent in individuals. After identification, individuals internalize and invest in developing those talents into strengths. When individuals identify and internalize their strengths, they feel more satisfied and fulfilled (Park \& Peterson, 2008). This internalization leads to the third phase, changes to individual behavior (Clifton \& Harter, 2003; Hodges \& Clifton, 2004).

\section{Positive Psychology in the Workplace}

Employees who have higher levels of autonomy, challenging work, social interaction, choice, and competency are more satisfied and engaged in their work (Turner, Barling, \& Zacharatos, 2002; Carter \& Page, 2009). Additionally, recent studies in corporate and educational settings have shown positive outcomes, including increased productivity and employee engagement (Hodges \& Clifton, 2004). Managers who employ positive psychology and strengths-based approaches double the likelihood of success for themselves and their organizations (Clifton \& Harter, 2003). 


\section{Criticism of Positive Psychology}

Exponents of positive psychology have two main criticisms of its foundational premises: first, psychologists point out that it is difficult, perhaps even negligible, to focus on positive features of the human experience separate from negative traits (Guignon, 2002). It is those negative features that also make us human (Martin, 2006). Second, Miller (2008) argues that positive psychology employs circular reasoning that reduces the human experience to a list of positive attributes required to live a good life and negative attributes that should be avoided. "Both optimism and pessimism, so far as they have descriptive or explanatory value, must surely be counted as traits or features of a healthy, mature, balanced outlook" (p. 599). These critics point to the importance of employing a scientific method and analytical wariness to the study of positivity, happiness, and fulfillment in order to resist the urge to devolve into the realm of selfhelp pseudoscience.

\section{Principals as Transformational Instructional Leaders}

Modern educational researchers widely agree that instructional leadership is a vital role of the building leader (Nidus \& Sadder, 2011; Wallace Foundation, 2010; Ovando \& Ramirez, 2007; Neumereski, 2012; O’Donnell \& White, 2005). As expectations for principals have evolved to place an increased emphasis on instructional leadership, models such as transformational, servant, and authentic leadership have become the focus of much educational research (Hallinger, 2003; Beck, 2014; Collins, 2011; George, Sims, McLean, \& Mayer, 2011). Transformational leadership requires that the leader engages with and empowers followers, acting as both an encourager and challenger to individuals and the organization (Northouse, 2016; Rooke \& Torbert, 2005). Transformational leaders contribute to the satisfaction and growth of their followers (Turner, Barling, \& Zacharatos, 2002); they "care for the work-related 
development of their employees" (p. 721). Therefore, the movement toward an increase in transformational leadership at the building level has set a prime breeding ground for strengthsbased philosophy and practice as a means to improve teaching.

\section{Evolution of Teacher Evaluation}

Teacher evaluation systems are the primary way of measuring teacher effectiveness in the classroom (Weisberg, Sexton, Mulhern, \& Keeling, 2009). The ways in which principals currently evaluate teachers have their roots in the scientific management movement that accompanied the industrial revolution (Marzano, Frontier, \& Livingston, 2011). After World War II, Cogan (1973) and Goldhammer (1969) promoted a holistic, clinical method of evaluation that, in some ways, resembles systems of evaluation that are currently in place. Despite its original intent, the holistic model was reduced to teacher evaluation wherein supervisors looked for specific and predictable lesson structure, activities, and outcomes, and ignored the most critical variable in student learning, the individual teacher (Marzano, Frontier, \& Livingston, 2011). Several recent reports have critiqued current evaluation systems. Toch and Rothman (2008) claim that current evaluation methods are more concerned with credentials than learning. Other authors explain how clinical evaluation practices have resulted in the assumption that all classrooms, and the teachers who run them, should look and act the same and produce the same results (Weisberg, Sexton, Mulhern, \& Keeling, 2009). Current observation models focus on deficiency instead of strengths, and teachers' and principals' voices have been largely absent in designing evaluation systems (Ovando \& Ramirez, 2007).

\section{Teacher Observation and Feedback}

Teacher observation is an authentic and essential activity in teacher evaluation systems (Zepeda, 2006). Former qualitative studies have found that both principals and teachers value 
walk-through observations and feedback as one of the most accurate ways to show what is really happening in the classroom (Ovando \& Ramirez, 2007; Ovando, 2001). Teacher observation has a positive impact on both teacher growth and student performance. "Data showed that students of teachers observed more frequently collectively had greater gains in the performance of their students than those who had fewer observations" (Shaha, Glassett \& Copas, 2015). Observations that are informal, unannounced, short, and frequent throughout the year are most impactful to teacher growth and student learning (Marshall, 2005; Marshall, 2012).

Feedback is a crucial component of observation and essential for maximizing employee engagement and growth (Turner, Barling, \& Zacharatos, 2002). Frequent and specific feedback is necessary for a comprehensive evaluation program (Weisberg, Sexton, Mulhern, \& Keeling, 2009). However, in a study of over 15,000 teachers, nearly 74 percent reported that they received no specific feedback about their craft, and over half did not agree that evaluation improves teacher performance (Weisberg, Sexton, Mulhern, \& Keeling, 2009).

\section{Strengths-Based Coaching and Feedback}

Teacher observation accompanied by feedback is an important and necessary part of teacher evaluation programs (Anast-May, Penick, Schroyer \& Howell, 2011). However, in recent years, more research has focused explicitly on the benefits of strengths-based coaching and feedback. For this study, it should be noted that the term "strengths" refers to "an individual's ability to consistently provide near-perfect performance" in a specific activity, and that strengths derive from knowledge, skills, but most importantly from one's talents, which are innate qualities (Hodges \& Clifton, 2004; Clifton \& Harter, 2003). This definition of strengths is synonymous with what other researchers have called core qualities, competencies, or essential aspects (Ofman, 2000; Korthagen, 2002. 
In a quantitative study, Hiemstra and Van Yperen (2015) found that subjects who engaged in strengths-based identification and professional development activities to build on these strengths scored significantly higher than those who focused on improving their deficits in several areas: perceived competence, intrinsic motivation, and effort. In a more large-scale study, Van Woerkom and Myers (2015) found that employees who received strengths-based feedback rated their work-related satisfaction and performance significantly higher than those who did not work in strengths-based organizations. "To fully reap the benefits of using feedback, managers should instead primarily rely on a strengths-based approach to feedback that consists of identifying employees' areas of positive behavior and results that stem from their knowledge, skills, or talents" (Aguinis, Gottfredson, \& Joo, 2012, p. 106).

Feedback after observations should be specific, timely, and note teachers' strengths and positive teaching strategies (Marshall, 2012; Whitaker, 1997; Anast-May, Penick, Schroyer \& Howell, 2011). One effective way to structure feedback is by tying a specific teacher strength to a specific outcome of student learning as a cause-and-effect conversation (Aguinis, Gottfredson, \& Joo, 2012). This type of specific feedback inspires teacher self-reflection that results in improved teaching and learning in the classroom (Marzano, Frontier, \& Livingston, 2011). In summation, the literature is clear-principals ought to be transformational instructional leaders who engage in frequent, formative, and positive observation and feedback cycles with their teachers. Strengths-based leadership and coaching ought to garner positive results for employee performance; this study's goal was to start to bridge the gap between what ought to work in theory, and what is working in practice. 


\section{Research Design}

Lakeland Public Schools (a pseudonym) is a mid-sized district in mid-Missouri. For the last several years, the district has invested energy and resources into developing a strengthsbased culture of teaching and learning, including the implementation of CliftonStrengths diagnostic and training tools for building leaders and teachers. Lakeland also uses the NEE model for formal evaluation of teachers, and building leaders provide strengths-based coaching and feedback on a daily basis. In turn, Lakeland is an ideal case to examine the interaction of various policies to enhance strengths-focused instructional leadership. The following research questions guided this qualitative case study:

1. How do building leaders implement strengths-based coaching and feedback as part of teacher development and evaluation?

a. How do their attempts complement or conflict with other policies, such as the district/state teacher evaluation model?

b. How do they fit strengths-based coaching and feedback into their daily schedule?

c. In what ways has the implementation of strengths-based coaching and feedback impacted the leader's own leadership development?

This case study most closely aligns with the characteristics defined by Merriam (1998): focusing on a particular experience (e.g., strengths-based coaching and feedback), providing rich detail of the phenomenon, and being heuristic in nature (Yazan, 2015). This case study took place in a bounded system (a single school district in rural Missouri), and achieved triangulation by collecting multiple data points across four buildings with seven leaders and their followers. 


\section{Data Collection}

Participants for the study were chosen based on their roles (principals and assistant principals) as teacher evaluators and for their specific experiences with strengths-based coaching and feedback, including at least two years of training on 30 -second feedback specifically. The administrators represented a wide range of experiences and backgrounds, as shown in Table 1.

Table 1

Participant Demographic Information and Training Experiences

\begin{tabular}{|c|c|c|c|c|c|}
\hline $\begin{array}{l}\text { Participant } \\
\text { (pseudonym) }\end{array}$ & Age & Gender & $\begin{array}{l}\text { Years and Type } \\
\text { of Administrative } \\
\text { Experience }\end{array}$ & $\begin{array}{l}\text { Training in Strengths- } \\
\text { Based Coaching }\end{array}$ & $\begin{array}{l}\text { Additional Training in } \\
\text { Strengths-Based Coaching }\end{array}$ \\
\hline Ms. Carson & $40-50$ & $\mathrm{~F}$ & $\begin{array}{l}20+ \\
\text { Elementary }\end{array}$ & \multirow{8}{*}{$\begin{array}{l}\text { The entire team has } \\
\text { completed the following } \\
\text { strengths-based coaching } \\
\text { training over the course } \\
\text { of three years: } \\
\text { CliftonStrengths Training } \\
\text { (Gallup) } \\
\text { Strengths Coach Training } \\
\text { (Gallup) } \\
\text { Leadership Training } \\
\text { (RPDC/MLDS) } \\
\text { Onsite Coaching Lab } \\
\text { Experience (Consultant) }\end{array}$} & MLDS Cohort \\
\hline Mr. Edgar & $30-40$ & $\mathrm{M}$ & $\begin{array}{l}5-10 \\
\text { Elementary }\end{array}$ & & $\begin{array}{l}\text { MLDS Cohort } \\
\text { Gallup Strengths Summit }\end{array}$ \\
\hline Mr. Ellis & $40-50$ & $\mathrm{M}$ & $\begin{array}{l}10-20 \\
\text { Elementary }\end{array}$ & & \\
\hline Ms. Cardwell & $30-40$ & $\mathrm{~F}$ & $\begin{array}{l}5-10 \\
\text { Secondary }\end{array}$ & & $\begin{array}{l}\text { MLDS Cohort } \\
\text { Gallup Strengths Summit }\end{array}$ \\
\hline Mr. Martin & $50-60$ & $\mathrm{M}$ & $\begin{array}{l}5-10 \\
\text { Secondary }\end{array}$ & & \\
\hline Mr. Shank & $40-50$ & $\mathrm{M}$ & $\begin{array}{l}20+ \\
\text { Secondary }\end{array}$ & & Gallup Strengths Summit \\
\hline $\begin{array}{l}\text { Ms. Johnson } \\
\text { (researcher) }\end{array}$ & $30-40$ & $\mathrm{~F}$ & $\begin{array}{l}5-10 \\
\text { Secondary }\end{array}$ & & $\begin{array}{l}\text { MLDS Cohort } \\
\text { Gallup Strengths Summit }\end{array}$ \\
\hline Mr. Lindel & $30-40$ & $\mathrm{M}$ & $\begin{array}{l}5-10 \\
\text { Secondary }\end{array}$ & & \\
\hline
\end{tabular}

Data collection took place in the natural setting (principals' schools) and included a series of three semi-structured interviews adapted from Seidman's model of in-depth phenomenological interviewing (Seidman, 2006), which sought to understand both the structure and nature of strengths-based coaching as it fits into building leaders' daily workflow. Between the second and third interviews, the researcher observed leaders through a half-day of 
observation and feedback to collect data using a protocol that accounted for both objective observational data and the researcher's personal reflections and impressions of the data (Bogden \& Biklen, 1992; Creswell, 2016).

\section{Data Analysis}

In case studies, attention to data management is of vital importance to the study's success. As is the preferred method in qualitative research, data analysis coincided with data collection (Merriam \& Tisdall, 2016). The researcher analyzed each data set before moving on to the next step of data collection. Specifically, every participant took part in the first interview within the same week. After the first round of interviews, the researcher listened to each recording (in the same order the interviews were conducted) and took note of main points, themes, and significant statements. The researcher created a chart where responses were color-coded by participant and sorted according to their relevance in answering each part of the research question. Common themes were connected with arrows and paraphrased at the bottom of each column. This process was repeated after each round of interviews. From the paraphrased themes, the researcher continued the process of connecting main ideas to form a list of emergent themes (which began as a group of 14 ideas, which was later combined to eight themes, and finally distilled to four major findings).

This process was organized using Stake's (2010) assembly plan model so that both major themes, which appeared in several pieces of data, and patches, which are significant pieces of learning that only appeared in a few pieces of data, were both represented in the data analysis of emergent themes. In qualitative research, "reliability and validity are conceptualized as trustworthiness, rigor, and quality" (Golafshani, 2003, p. 604). To accomplish this, the researcher returned to the full data set (the chart from each round of interviews) and compared 
each statement to the emergent themes, and coded each statement with a number (coordinating to the summarized common theme), an asterisk (meaning the idea did not connect to a common theme but represented a significant patch in the researchers' mind) or a hyphen (meaning the statement did not relate to an emerging theme and also was not a significant patch in the data set).

This study ensured triangulation, defined as "a validity procedure where researchers search for convergence among multiple and different sources of information to form themes or categories in a study" (Creswell \& Miller, 2000, p. 126). Besides conducting three interviews per participant (21 total interviews), the researcher also analyzed data from observation field notes. The analysis was grouped in the same way the data was collected. At both elementary buildings and one secondary building, the administrators walked around as a pair and took turns implementing the 30-second feedback model; the analysis occurred after the observations and looked at the pair of participants as one data set (the seventh participant at the other secondary building was included in the data set with the other secondary principals). The observations took place between the second and third interviews but were the last set of data coded. The data was marked using the number/asterisk/hyphen coding described above. The field observation was also coded ( $\mathrm{S}=$ strengths, $\mathrm{P}=$ pedagogy) to represent principal identification of both instructional strategies and references to the use of specific strengths vocabulary. Finally, after distilling the information down to four main findings, the researcher revisited the detailed raw data (audio recording/transcript of interviews, field notes, and data charts) through the lens of the results to ensure validity and accuracy. 


\section{Overview of Findings}

Six weeks of data collection and analysis, seven participants, and hundreds of individual data points resulted in the initial identification of several themes. These common themes emerged despite the diversity of the leadership team and their instructional styles and across four buildings with different teachers and age groups of learners. First, leaders in this study valued strengths-based coaching because it increased their visibility and credibility as instructional leaders on a daily basis. Second, leaders implemented strengths-based coaching models with freedom, flexibility, and according to their own style. Third, leaders perceived both negative and positive links between strengths-based coaching and NEE. Finally, fourth, leaders' implementation of strengths-based coaching models has resulted in increasing leaders' personal knowledge of their pedagogical skills and leadership strengths.

\section{Theme One: Visibility and Credibility as Instructional Leaders}

All participants reported that since the implementation of strengths-based coaching and feedback in this district, their visibility in classrooms during the learning process has exponentially increased. In digging deeper, four of seven leaders said they are in every classroom before lunchtime, follow a prescribed "path" throughout the building, and spend from one up to five minutes in each classroom. During my observations, I noticed that students and teachers did not seem distracted by principals entering and leaving classrooms, it did appear to be the "norm;" in only one classroom (of over 20 visited) did a teacher stop the class to explain to the administrator where they were at in the lesson (Field Observation, Martin).

I also observed principals check in with several individual students during our visits. When asked how they determined which students to speak to, there were a variety of strategies for selection, but every principal commented that one benefit of being in every classroom was 
the ability to check on the emotional state of students with behaviors early in the day in order to prevent behaviors later in the day. Although outside the scope of data collected during this study, administrators believe that implementation of strengths-based coaching and feedback, including the goal of being more visible in classrooms, has had a direct impact on decreased discipline numbers at all buildings. "We have seen a huge decrease in classroom discipline issues, and I know part of it is that I make a point to check in with a handful of our most at-risk students every morning as I am doing observations" (Interview 1, Ellis). In the field observation, for example, I noticed Ms. Carson knelt down to have a short conversation with a student who had his head on his desk. When I asked about it in the hallway, she explained, "That was my opportunity to redirect him in the classroom. If I don't check on him in the classroom most days, I know he will be in my office before the day's over" (Field Observation, Carson). It is clear that while data might not exist to show a causal relationship between daily observations and a decrease in discipline, the participants perceive that there is a connection. So they count it as a value-add to strengths-based coaching and feedback implementation.

Principals also reported that visibility in classrooms has caused teachers to come to administrators with instructional concerns/questions more frequently than in the past. As explained by one principal:

Teachers who never would have come to me to have a serious conversation about instructional strategy seek me out because they know I have seen them teach every day this year. They feel like I know what is going on in the classroom and see me as an expert not only in instruction but in their classroom specifically. (Interview 1, Edgar) 
Another participant pointed out that visibility is always important, but the implementation of strengths-based coaching and feedback has provided an avenue to achieve that during the school day — it is part of the expectations from central office (Interview 3, Lindell).

\section{Theme Two: Freedom, Flexibility, and Fidelity of Implementation}

\section{Leaders Implemented with Variation}

While all of these administrators have gone through the same training and lab experience regarding 30-second feedback, there were marked variations in how they practically implemented the model. Section 2, Figure 3 displays the appropriate implementation of 30 second feedback and includes the following elements: introduction (gratitude), teacher cause (specific strength observed), student impact (specific student actions in response to instruction), positive tag. Over the course of seven field observations (21 individual teacher observations), I saw at least seven different variations of this implementation. Interviews with the teachers support this .....(claim) .... For example:

I know that we are supposed to only pick one specific strategy or strength we observed, but rarely can I only pick one. So I try to pick one strategy and one personality trait of a teacher so I don't overwhelm them with too much information. (Field Observation, Ellis) Ms. Cardwell pointed out that she sends written feedback because she doesn't feel as articulate or authentic in the moment. "Plus, when I go to do a summative evaluation, I already have all this great data saved from my observations throughout the year" (Interview 2, Cardwell). Mr. Shank also articulated that he preferred written feedback, too, even though officially (or per the policy), 30-second feedback requires face-to-face feedback. I asked Ms. Carson about face-toface feedback versus written and whether she saw a problem with the different modes of feedback. She responded, "It's all about delivering the most effective communication. Some of 
us are better in the moment; others need to process. The point is that the teacher is getting quality, immediate feedback" (Interview 3, Carson).

Three of seven principals asked questions during the 30 -second feedback, which is not part of the established protocol. Mr. Ellis explained, "When I phrase the strength as a question, it gives the teacher an opportunity to shine, and I think they remember it longer than if I did all the talking" (Field Observation, Ellis). 30-second feedback ranged in time from 28 seconds to two minutes; there was no correlation between the average length of feedback and strict adherence to the 30 -second feedback protocol. Notably, none of the participants were able to average close to 30 seconds, as show in Table 2.

Table 2

Average Length of Feedback during Strengths-Based Field Observation

\begin{tabular}{|l|l|l|}
\hline Research Participant & $\begin{array}{l}\text { Followed Prescribed 30- } \\
\text { Second Feedback Protocol or } \\
\text { Diverged from Model }\end{array}$ & $\begin{array}{l}\text { Average Length of Feedback } \\
\text { (in seconds) }\end{array}$ \\
\hline Carson & Followed & 57 \\
\hline Edgar & Followed & 105 \\
\hline Ellis & Diverged & 87 \\
\hline Cardwell & Followed & 60 \\
\hline Martin & Diverged & 117 \\
\hline Shank & Diverged & 48 \\
\hline Lindell & Followed & 93 \\
\hline
\end{tabular}

In the third and final round of interviews, I asked participants about the variations both in style and length of feedback. "[Our trainer] would probably get onto us about that" (Interview 3, Edgar), responded, but Mr. Edgar and others pointed to the variations in implementation as just another positive way in which strengths-based coaching and feedback takes into account both the strengths of the teacher being observed, and the strengths of the observer. "We are using our own strengths to coach people in their strengths" (Interview 3, Carson). All seven participants 
referenced one or more of their own CliftonStrengths throughout the interview process and connected that to how they implement strengths-based coaching and feedback with teachers. Mr. Ellis is a relator, and that is why he frames his feedback as questions- - he wants to "let the teacher make connections" (Field Observation, Ellis) between their teaching and positive student outcomes. Mr. Shank has individualization as a top strength. He pointed out that he always looks to point out the uniqueness in his teachers and encourages them to grow in their unique talent instead of trying to imitate other teachers on their team (Interview 3, Shank).

At the heart of this second theme is the idea that strengths-based coaching and feedback is, by nature, informal and adaptable to both the building leader's own style, strengths, and instructional expertise and to the specific contexts in which it is being implemented. Leaders had several positive responses to the ways they were implementing 30 -second feedback, but they had one common barrier that came up in both the interviews and observations - the difficulty of ensuring face-to-face feedback with teachers.

\section{Leaders Struggled with Face-to-Face Feedback}

As suggested by the variability detailed in the preceding section, the biggest concern raised by building leaders about strengths-based coaching and feedback, and 30-second feedback specifically, was the difficulty in giving that immediate face-to-face feedback to teachers. Some barriers included not wanting to interrupt the flow of learning in the classroom, not timing observations to coincide with an upcoming break for that teacher, and the principal being pulled away mid-observation and not having time to circle back around to that teacher. Every principal reported that getting into classrooms was easy, but giving feedback was difficult. "I see what every teacher is doing every day. I can't possibly give feedback to every teacher, or even a handful of them and do the rest of my job" (Field Observation, Lindell). One participant 
estimated that while she may get into $100 \%$ of classrooms every day, she only gives feedback in any form to less than 10\% of those teachers (Interview 2, Carson). The barriers to providing immediate feedback were evident coming out of the second round of interviews, so a decision was made to modify the field observations in order to overcome those barriers so that face-toface coaching could be observed.

For this study, the field observations were structured in such a way to allow for immediate feedback. The field observations were completed in leadership pairs; both principals and the researcher walked the building. One principal would cover the class while the other gave 30 -second feedback to the teacher in the hall after each observation. However, this is not necessarily how strengths-based coaching was being implemented on a daily basis outside of the case study. Sometimes leaders would walk around in pairs, but they were also accustomed to implementing strengths-based coaching alone in their daily practice.

The field observation also exposed an important distinction between the implementation of 30-second feedback in the elementary versus the secondary level. All four elementary teachers said that the observation experience could easily be duplicated without the presence of the researcher. In fact, they made plans to continue this structure (going around the building as a pair) in the future. The reason, it seems, is that it was relatively easy for one principal to step in for an elementary teacher due to the fundamental nature of the content and curriculum, while the other could provide the immediate feedback; that is, the principal subbed in with relative ease and little distraction to students. However, at the high school level, the classroom learning/instruction ceased while the teacher came into the hallway for 30-second feedback. In other words, “it doesn't matter if you bring someone with you to help cover the teacher-I can't take over and teach AP Chemistry while [another leader] gives feedback in the hallway. Not 
possible" (Field Observation, Martin). All three secondary principals reported that this implementation of strengths-based coaching wasn't feasible in the future because of the high distraction to student learning.

When all participants were asked if they had found a better way to implement 30 -second feedback in practice, several pointed to the act of putting 30 -second feedback into written form as still being powerful for the teacher. Mr. Edgar uses voice recording on his phone and sends the teacher oral feedback through text message from the hallway after an observation. Mr. Shank said that he selects three teachers (of all he was able to observe that day) and makes a point to stop by their rooms on their plan period to provide feedback, though he wishes he could do that for every teacher, every day. Ms. Cardwell often handwrites her strengths-based feedback in a thank you card that she leaves in the teacher's mailbox.

\section{Personal Discipline Required for Implementation with Fidelity}

Implementation of strengths-based coaching is simple but requires intentional planning, accountability, and a willingness to let go of other tasks. After the observations, the researcher sat down with each administrator for the final interview to debrief about the experience. Over and over, each administrator commented on how easy and straightforward 30-second feedback is to implement. As one administrator put it, "All I'm doing is telling a teacher what I saw. And no one can argue with that, because it's what I saw" (Interview 3, Edgar). Another leader pointed out, "I'm walking into a room to help teachers see how their instruction impacts student learning - it's as simple as that. And once they are aware of that, they are constantly trying to improve their instruction" (Interview 3, Lindell). So, when asked why they have not implemented it at a higher level, every principal pointed out the need for greater intentionality in managing their time. Blocking off time in one's calendar, making a list of which teachers would 
be receiving 30-second feedback each day of the week (to account for all teachers), and planning visits that coincide with upcoming teacher plan periods are all strategies principals would like to implement in the future.

Principals also want to recreate the level of accountability they faced when agreeing to participate in this particular study. At Lakeland Public Schools, the administrative team (principal and assistant principal) in each building has to hold each other accountable, even coordinating schedules to block time together to ensure strengths-based coaching and feedback is happening every day. This is not necessarily the organizational structure of all school district administrative teams (as discussed further in the implications section). And finally, several principals commented on the need to "let go" of other administrative tasks in order to focus more time on observation and feedback. What exactly can be "let go" is up for debate. One common theme was the idea that duties such as returning phone calls and answering emails could wait until later in the day, but often the need to deal with issues immediately got in the way of instructional leadership. As one principal put it, “Anything that doesn't involve interaction with teachers or students should really take a backseat when teachers and students are in the building" (Interview 2, Carson).

\section{Theme Three: Strengths-based coaching and its interaction with NEE.}

During the second interview with each building administrator, I asked each to describe how strengths-based coaching, and specifically the 30-second feedback model, worked within the district's formal NEE evaluation system. When asked about this, administrators commented that they were able to shift seamlessly between strengths-based and NEE observations. Digging deeper, Mr. Lindell compared the models: both require short observations, the principal to look for teacher actions and the impact to student learning, and specific and timely feedback 
(Interview 2, Lindell). While the specific protocols may differ, and NEE requires documentation during the observation, building leaders perceived that these two types of evaluation could peacefully coexist.

When I walk into a room, I have three options. I can just observe the class and leave, I can observe and give strengths-based feedback, or I can observe and complete a formal evaluation; I don't necessarily know when I walk into the room what direction the observation is headed. (Interview 2, Shank)

When I pressed leaders on how the implementation of 30-second feedback and strengthsbased coaching strategies in general has impacted the use of the formal evaluation system, leaders expressed a few common responses. NEE evaluations became much easier and took a shorter amount of time, since the administrator was very familiar with both the instructor's skillset and where students were in the learning process in the classroom. "I can knock out a NEE observation and give feedback within five minutes, where it used to take me 15 minutes to observe and 15 minutes to document feedback. I know exactly what is going on in that teacher's room when I walk in" (Interview 2, Martin). Additionally, although NEE's intention is to be used as a formative growth tool (just like strengths-based coaching models) Ellis, Shank, Lindell, and Carson all made comments about NEE losing its power to either bolster or bother teachers. It had become a more summative tool, "a hoop" (Interview 2, Lindell), "not as inspiring" (Interview 2, Shank), and "less impactful than our strengths-based coaching conversations" (Interview 3, Carson).

Given these responses, it seems that the formal district evaluation tool has become a less significant and time-consuming tool in teacher development; participants viewed this as a positive effect. However, a more worrisome finding (perhaps for the creators of the NEE 
system, but not so much for this sample of administrators) was the perception by several principals that the implementation of strengths-based coaching has caused an inflation of NEE scoring over the course of the last two years. As one principal reported:

I am much more likely to give teachers the benefit of the doubt when it comes to NEE scoring, especially if I didn't see it [a specific criteria] during that particular observation, but I know it's something I normally see in their classroom (Interview 2, Edgar).

Similarly, Martin (Interview 2) said that because he has seen the value of the postobservation conversations coming out of the strengths-based coaching model, he inflates the NEE number score so teachers focus on having a great conversation about learning instead of the number. When I pushed back on this idea, that perhaps inflation of formal scoring was having a negative impact on teacher growth, principals quickly disagreed. Leaders pointed to the increase in teacher conversations around instructional strategy, both with each other and administration (Field Observations, Edgar \& Carson), the willingness to take risks in the classroom and fail forward (Field Observation, Shank), and the positive culture toward teaching and learning as positive benefits that outweigh inflation of formal scoring (Field Observation, Ellis).

The overarching conclusion is that the NEE evaluation had become less important in buildings where principals were implementing strengths-based coaching at a high level, and was more of a formality, or as a tool to document teachers on track for non-renewal, than it was a growth tool as was intended by its creators.

\section{Theme Four: Leaders Increased Knowledge of Own Strengths and Pedagogical Skills}

A question in the first interview dealt with how training and implementation of strengthsbased coaching and feedback had impacted each leader's own development. Without fail, every leader pointed out that first and foremost, this training led them to discover more about their own 
strengths, to "name, claim, and aim" their strengths toward their own leadership tasks and the development of teachers.

One of my top strengths is developer, and I lean into that every time I interact with a teacher. Strengths-based coaching has allowed me to see every interaction as an opportunity to build up someone else. Before this training, I felt like I was more focused on pointing out weaknesses and reacting to problems in the classroom. Now I approach leadership completely differently. (Interview 1, Carson).

Throughout the series of interviews, each leader constantly pointed out not only their own strengths, but could easily speak to the strengths of several staff members, and each teacher's room that we visited. Besides the clear focus on strengths and use of strengths terminology, leaders' responses to interview questions and comments to teachers to the field experience were saturated with deep pedagogical understanding.

At the completion of data collection, I reviewed all data points to also code for use of strengths terminology and pedagogical language. I noticed that these principals, whether they had decades of experience or a few years, seemed to pepper these concepts into their conversation with impressive frequency. "We require our teachers to use academic vocabulary in the classroom, so I ought to be using pedagogical vocabulary every day with teachers to increase their understanding" (Field Observation, Cardwell). During observations, I noticed that whether the principal was commenting on a teacher's innate talent or a specific instructional strategy, they were using these specific terms and explaining them with authority. In other words, these principals all seemed to be expert instructional leaders, and I thought it strange that all seven building principals in one district would have such a high level of instructional leadership skills by chance. 
When asked about this in the final interview, many principals made a direct connection between their use of strengths-based observation and feedback and their increased knowledge and use of pedagogical terms. Four of the leaders are currently involved in the MLDS program through the state of Missouri, four of the leaders have pursued advanced degrees (doctorate) since being trained in strengths-based philosophy, and many reported an increase in individual professional development through reading and research to hone their skills. Even one principal who expressed some skepticism about the use of strengths-based feedback models pointed to the fact that one of the reasons he had negative feelings toward strengths-based coaching is because he felt inadequate in his understanding of effective pedagogical skills.

\section{Summary of Findings}

These seven instructional leaders are committed to continuous learning by making sense of and implementing strengths-based coaching and feedback in their context. Through a series of interviews and observations, the following four themes emerged: first, leaders in this study valued their increased visibility and credibility as instructional leaders; second, leaders implemented strengths-based coaching models with freedom and flexibility, but struggled implementing with fidelity to the true protocol model; third, leaders' implementation of strengths-based coaching interacted in both positive and negative ways with formal district evaluation models; and fourth, leaders' implementation of strengths-based coaching models resulted in increasing leaders' personal knowledge of their pedagogical skills and leadership strengths. Figure 5 summarizes the major themes as they related to the research question. 


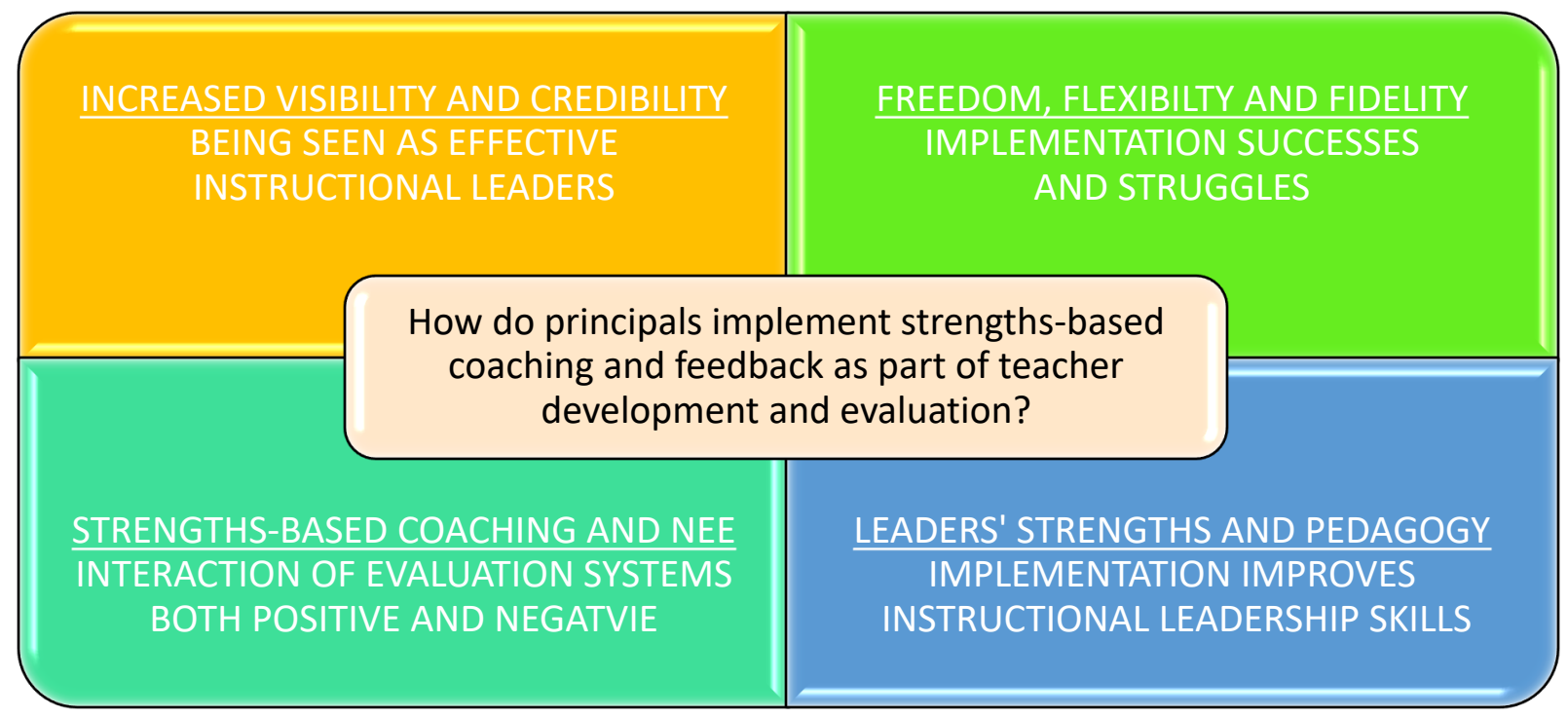

Figure 5: Summary of Themes.

\section{Limitations, Implications, and Significance}

One important limitation of this study was that because the participants were purposefully chosen due to their homogenous philosophy on instructional leadership, common training in strengths-based coaching, and their roles in this specific bounded system, this study was limited in that it did not explore the intersection of strengths-based coaching and feedback in the daily lives of all types of building leaders. A second possible limitation regarded my role as both researcher and colleague to the participants in the study. The research was seen through the lens of my own experiences and preconceived notions with strengths-based coaching and feedback. Also, being a colleague to the participants may have made it more difficult for principals to share their negative perceptions, failures, or obstacles for fear of seeming incompetent. To mitigate this limitation, we had an upfront and honest conversation before the first interview to both revisit the purpose of the study, the confidentiality of the process, and my openness to set aside any personal bias with the goal of discovering themes based solely on the participants 
experiences separate of my own. My goal was to proactively mitigate this limitation so that my role as a trusted colleague would lead to a open, honest, and in-depth experience.

This study has several implications for both researcher and participants. First, this study provides both a chance for each building leader to reflect on his or her own practice, and also to learn from others' experiences in a way that is largely impossible during the school year. All of these participants have attended training in strengths-based feedback and have even been lucky enough to participate in a lab experience where they practiced applying their skills, but none of them have had the opportunity for deep reflection and analysis of their training in practice.

Second, the research has implications for transformational instructional leadership in practice. Although this qualitative case study centered around the perspectives of a very specific group of leaders with a common (but unique in the general context of education) strengths-based training and approach to coaching, the implications for instructional leadership across contexts are important. Calabrese \& Zepeda (1999) found that despite the extant literature on the benefits of the principal as instructional leader, in practice principals are unable to put theory into practice amidst all the other requirements of their daily work. The results and analysis of strengths-based coaching and feedback provide for practical ways to move principals closer to the ideal definition of instructional leader, and implies that it is possible for leaders to capture one of the most important tenants of instructional leadership: empowering others to reach their maximum potential (Northouse, 2016).

Third, the study has implications for the use of formal teacher evaluation models such as the NEE. A major theme of the study revolved around the intersection of strengths-based coaching and feedback and NEE, and found that there are both positive and negative impacts to the formal evaluation model. Further studies should be done to examine how to incorporate 
strengths-based coaching as part of a formal evaluation process in a way that maximizes teacher performance but also preserves the validity and accuracy of formal tools, or whether strengthsbased coaching has a greater impact to teacher performance and self-efficacy than current formal evaluation tools - in this case, results could cause sweeping policy reform to evaluation models across public education.

This case study was born from the researcher's desire to grow as an instructional leader and developer of classroom teachers. Collecting the stories of colleagues and watching each of them apply their skills in unique and inspiring ways helped to make sense of how strengthsbased coaching can be implemented in a way that changes administrators' daily practice by increasing visibility, credibility, instructional leadership founded in strengths, and pedagogical knowledge. In the end, I found that rather than focusing on following a strict feedback protocol, leaders should focus on authenticity and specificity of feedback as opposed to the method in which its given. Future studies can build on this knowledge gained by looking for measurable and replicable growth for leaders and teachers who subscribe to a strengths-based philosophy of teaching, learning, and leading. 
Section Five: Contribution to Practice 
The final section of this dissertation represents my contribution to practice based on the findings of this study. I will present the findings, recommendations, and implications in the form of two coaching workshop experiences for administrators. An introductory workshop has been submitted to various educational development workshops including the Missouri Association of Secondary and Elementary School Principals' (MOASSP, MOAESP) annual conference.

\section{Growing Teachers 30 Seconds at a Time (workshop abstract)}

Are you a building leader who wants to grow teachers but something ALWAYS seems to get in the way? Join Staci Johnson as she explains a framework for instructional leadership that brings teacher development to the forefront and makes it possible to incorporate into your daily workflow. Participants will come to a deeper understanding about strengths-based coaching and feedback through the use of the 30 -second feedback model, observe and practice, and make a plan to implement 30-second feedback in every classroom, every day at your home school.

\section{Workshop Materials}

The workshop will be presented in person using Keynote slides as a visual aid. Keynote is a dynamic program which allows for sleek design that adds to, but does not distract from the speaker, and can seamlessly integrate video, words, and still photos as needed.
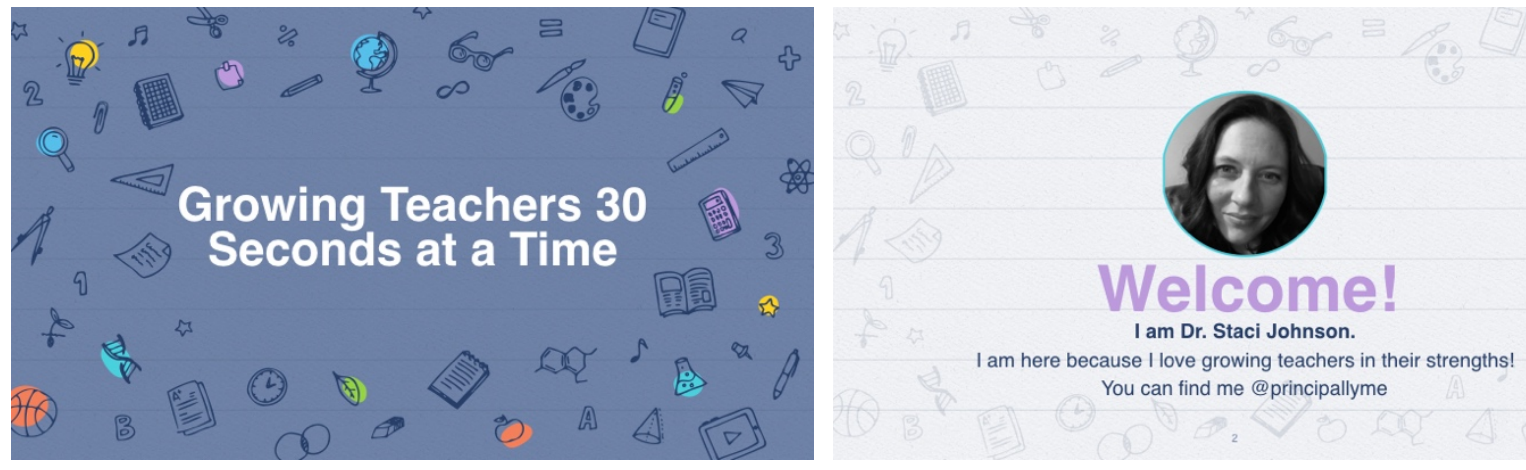


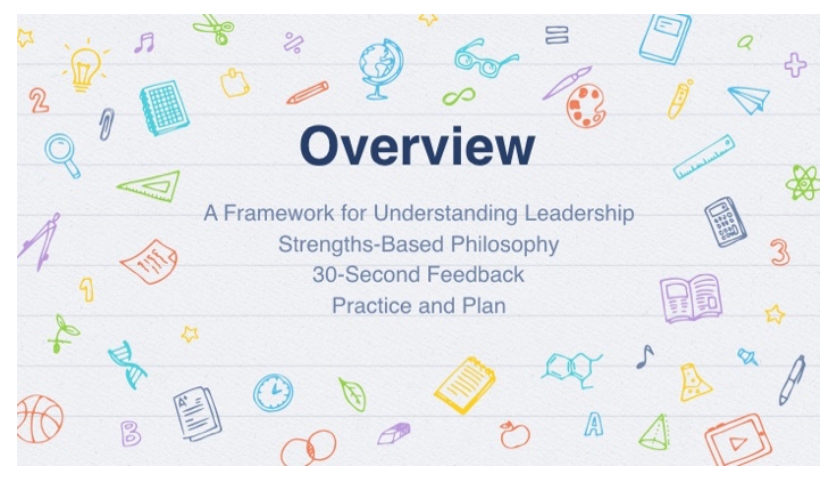

\section{$\because-0$ Principal \\ Brevity \\ Fragmentation \\ Diversity}

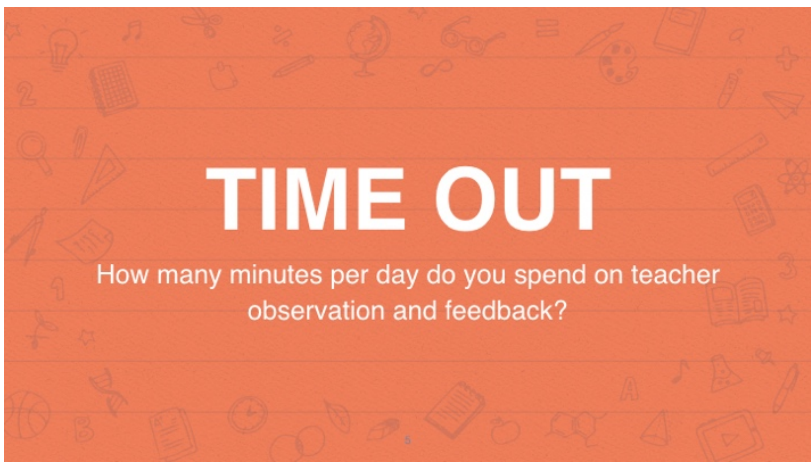

A Logic Model of Instructional Leadership
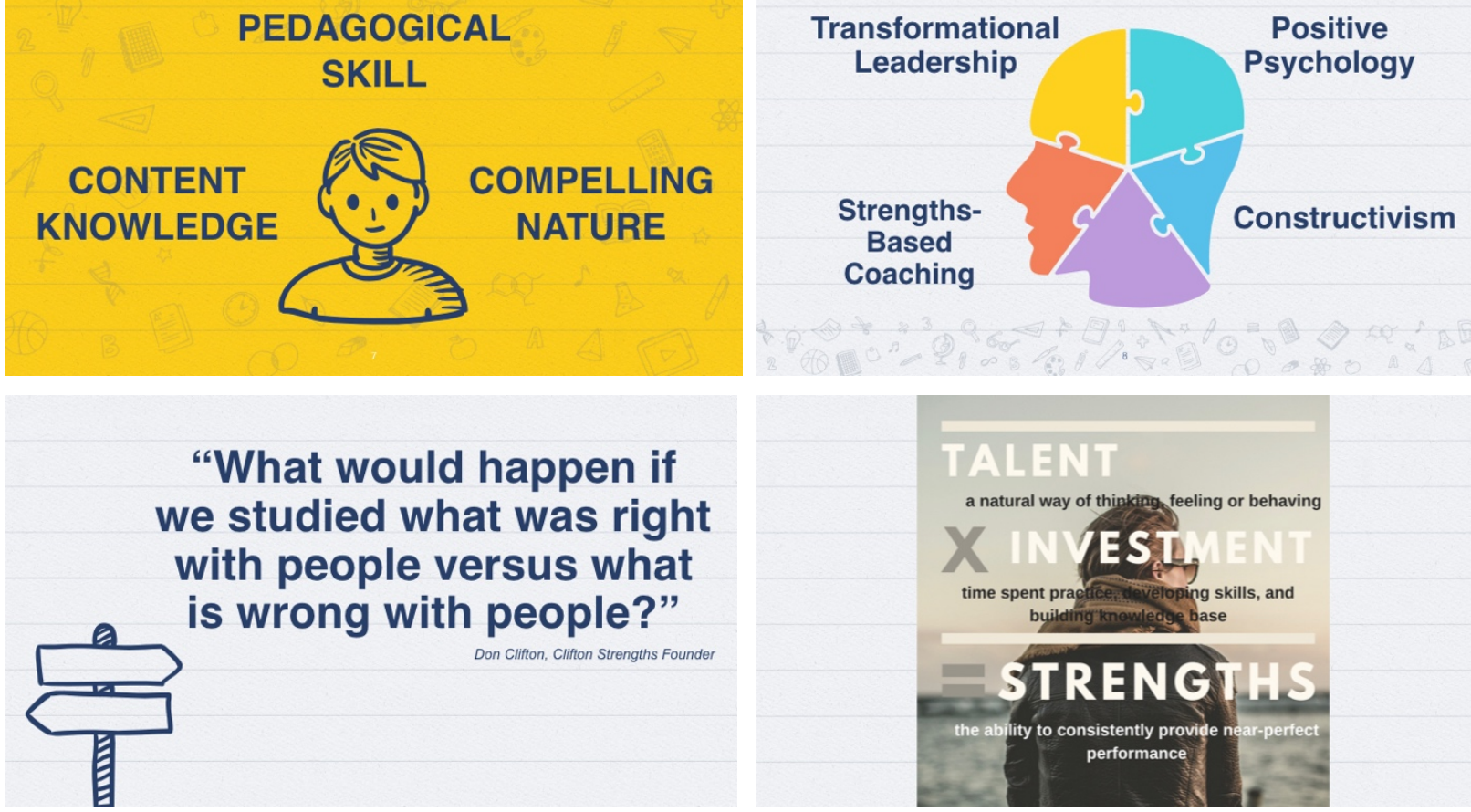


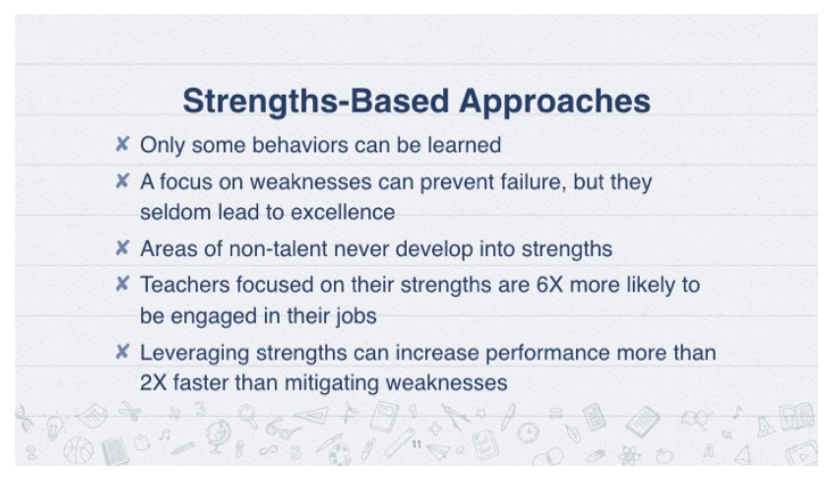

7 Tools for Developing Teachers and Teaching

\section{Rutherford Learning Group}

\section{Instructional Leaders know Instructional Practice}

$x$ Current Researchers

$x$ Comprehension Strategies

$x$ Engagement Strategies

$x$ Management Strategies

$x$ Critical Thinking Strategies
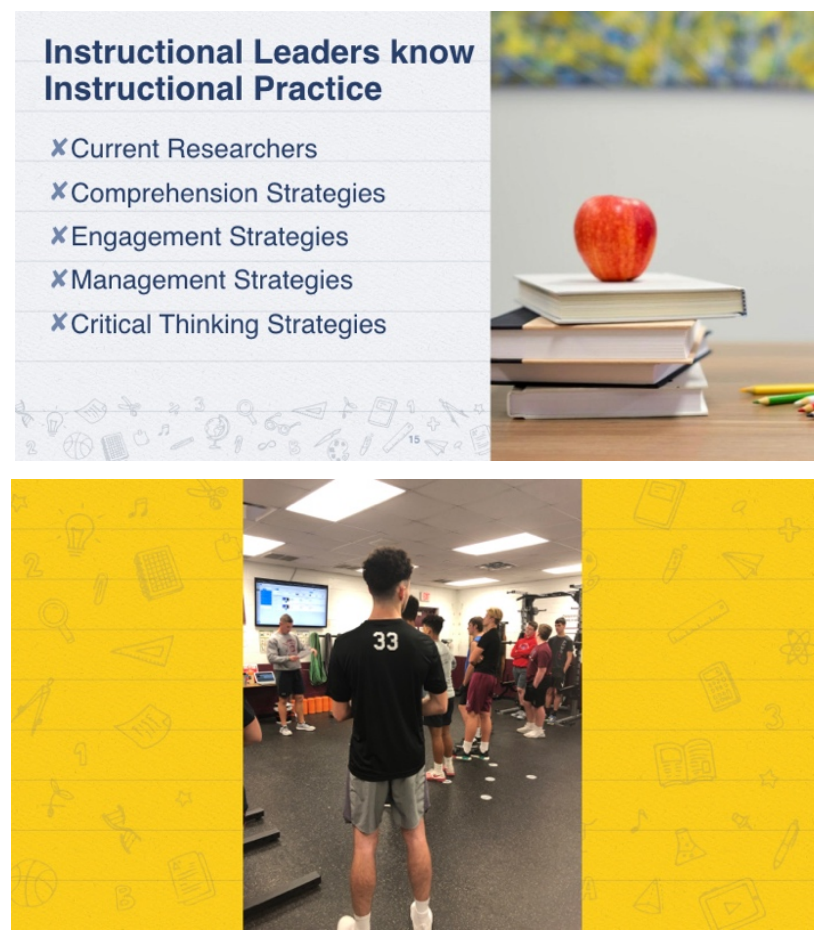

\section{TIME OUT}

Can you name the specific talents or instructional strengths of every teacher under your supervision?

\section{Second Feedback Protocol}
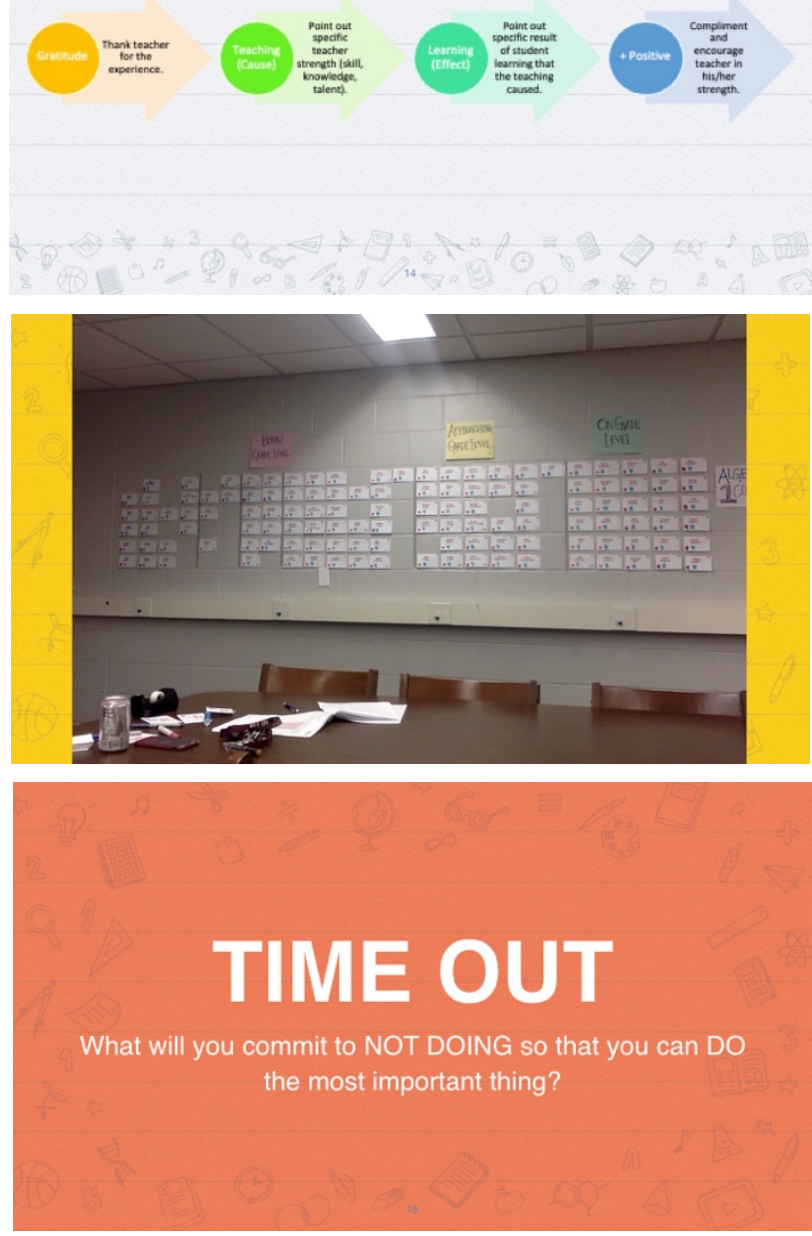

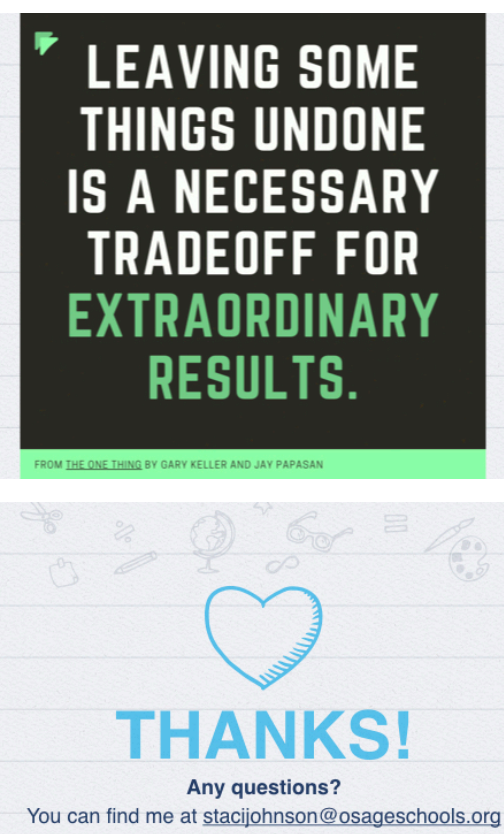

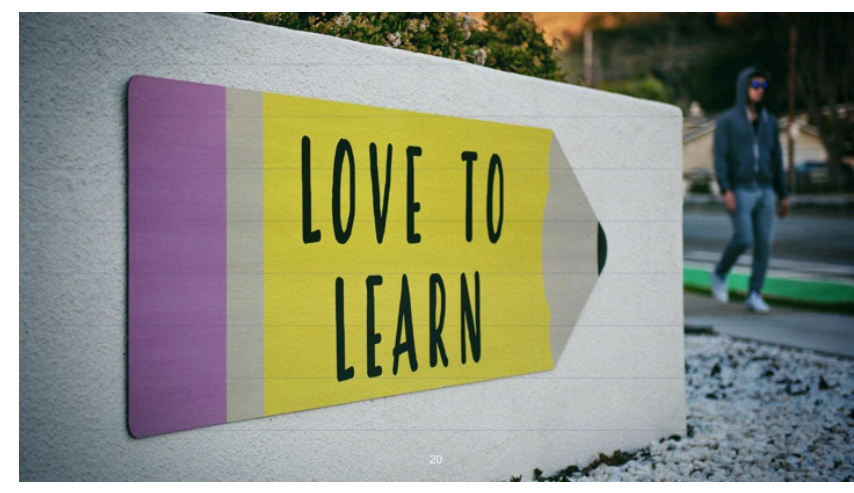

\section{Credits}

This presentation is a compilation of research from:

$x$ The Rutherford Learning Group

$x$ Gallup, Inc.

$x$ Missouri Leadership Development System Resources

$x$ Full List of Resources and Citations

Special thanks to all the people who made and released these awesome resources for free:

$x$ Presentation template by SlidesCarnival

$x$ Photographs by Unsplash

\section{In-Depth, Continuous Training}

A more aspirational (3-5 year goal) would be to partner with school districts in the state of Missouri to provide continuous training on the why, what and how of strengths-based coaching and feedback, and then to observe and coach administrators in the field throughout the year as they work to develop their teachers. The main goal of this contribution would obviously be to grow leaders in their effectiveness as instructional leaders, but this more in-depth plan for living out the research would most likely involve the researcher in a role as a paid consultant.

The year-long training would consist of 7-8 half-day workshops which integrate the findings (themes) of this research study; I have included a workshop document that would be sent to area superintendents as a way to advertise and recruit partner districts. This contribution to practice is appropriate and effective because it puts the "action" in "action research," and the "practitioner" in "scholarly-practitioner." 


\section{The Strengths-Based Instructional Leader}

\section{A Training Series for Building Principals and Instructional Coaches}

Through eight in-person half-day sessions for your administrative team, consultant Dr. Staci Johnson (whose experiences span from the classroom to the principalship to central office administration) will work with your team to understand best practices around transformational, strengths-based instructional leadership. This is an interactive training program that will take place on your campus, where principals will implement their learning with teachers in their own context while Dr. Johnson provides coaching and feedback to the administrative team. The training program can be adapted to meet the professional development needs and time constraints of your

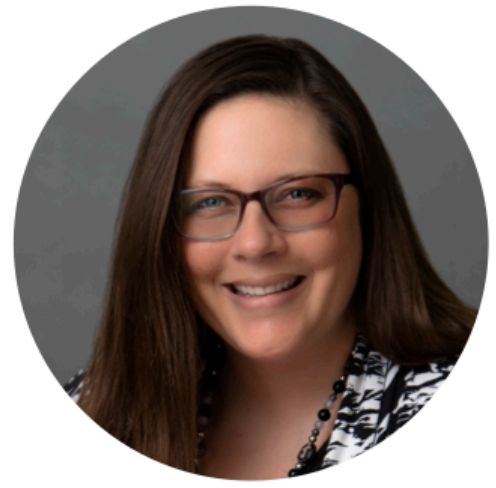
particular district. Your administrators will leave feeling confident and prepared to give high-quality feedback to teachers; the immediate impacts will be an improved culture around teaching and learning, and sustainable teacher and leader growth. Please contact drstacijconsultant@gmail.com

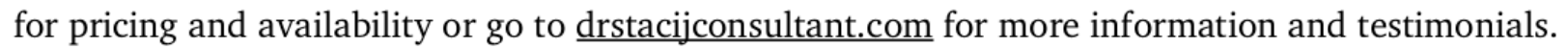
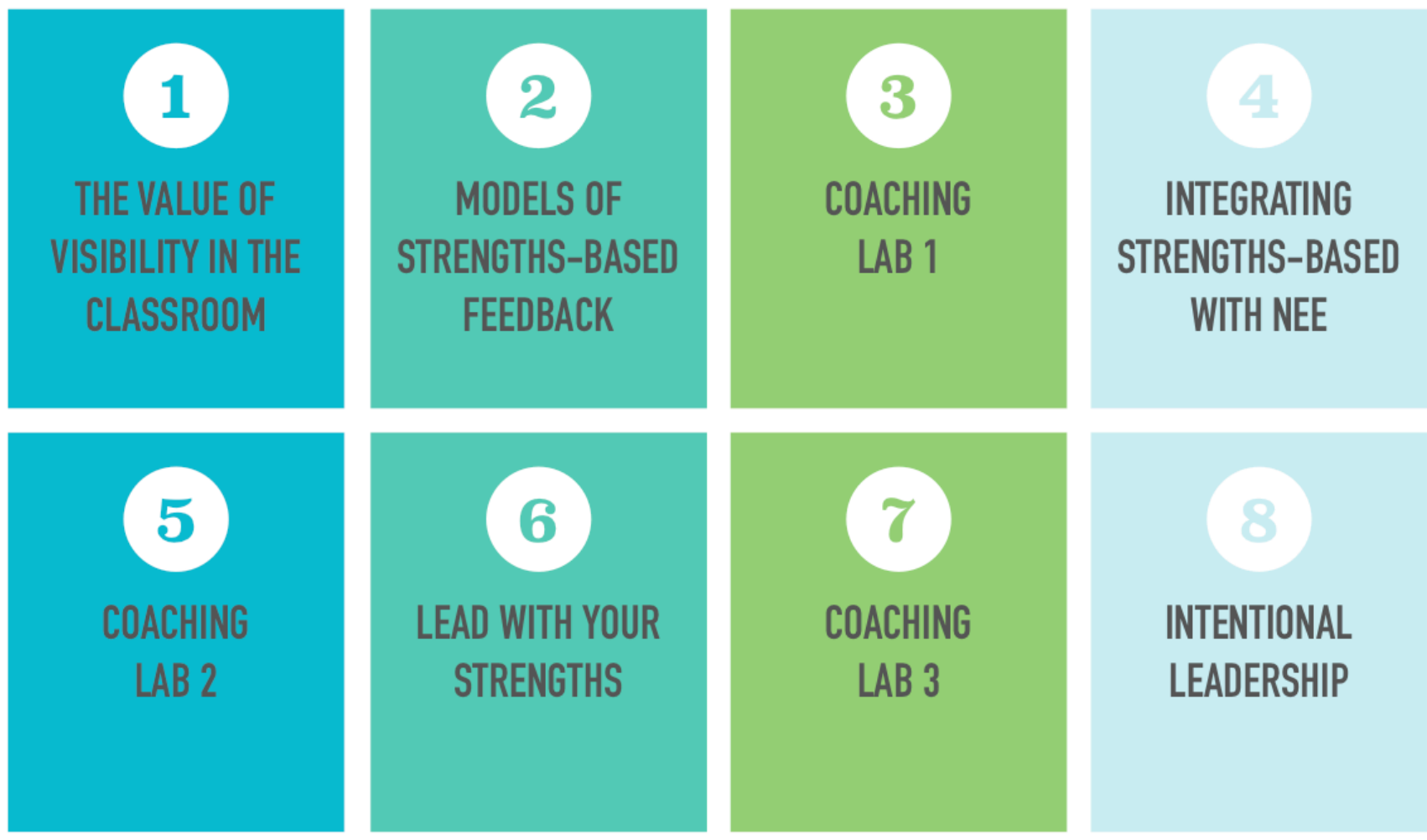
Section Six: Reflection on the Dissertation Process 
This dissertation has been four years in the making, ever since I showed up at Doctor Camp in the summer of 2017. But in reality, this dissertation is the culmination of my entire educational and professional career that has spanned 19 years of collegiate learning experiences and 15 years as a professional educator. It is hard to separate any of my previous experiences from this labor of love-I became a teacher because I wanted to guide young people to reach their greatest potential, I moved into the principalship because I saw how I could impact adults through coaching and development, I began this program because I needed to satisfy my own strengths as a learner and intellectual, and I chose this topic because I truly believe in the power of strengths-based coaching to change people's lives for the better.

And so, the dissertation seems to be a natural progression of my own development as a learner and leader, but it would be remiss of me to reflect only through rose-colored glasses; the

truth is, the journey to dissertation completion has also been fraught with some of the darkest and loneliest seasons of my adult life, shedding a light on some of the insecurities I have hidden deep inside, and forcing me to face fears and overcome adversity on the path to Doctor Johnson. In this reflection, I will discussion how the dissertation process impacted both my educational leadership and my identity as a scholar.

\section{Dissertation Process Impact on Educational Leadership}

I began my doctoral program when I was three years into my role as assistant high school principal. I am a firm believer that there is no chance to life, that each experience has a purpose, and I would say this program and the dissertation process came into my life at the exact moment that I needed. I had my feet under me as an educational leader, and I needed that next mountain to climb in my own professional development. The dissertation process has impacted 
my educational leadership in three ways: I am more knowledgeable, I am more reflective, and I am better connected.

\section{The Power of Knowledge}

This may seem like an obvious impact of working on a years-long research paper, but the dissertation process takes knowledge acquisition to the next level. I have always enjoyed learning more about my craft (teaching and leading); I am constantly reading books and articles to help me in my leadership. But there is a huge difference between reading popular educational blogs and books, and doing the in-depth research necessary to write the dissertation. Through researching the theoretical framework for this dissertation, I discovered more about why I lead the way I do, what I believe about leadership, and how to leverage my beliefs into my daily work. I dug into strengths-based psychology in a way that goes far beyond my initial training in CliftonStrengths. I have applied the knowledge gained during the writing process in how I develop the teachers in my care, and have become an expert on the administrative team in how we move our strengths initiative forward as a district. And it's important to point out, the dissertation process several times brought me to my figurative knees as it's the first time in a long time I read something (several somethings) that I did not understand, or was assigned to do something (statistical analysis) I didn't immediately know how to do well— the challenge of dissertation research can make even the highest over-achiever feel inadequate... which is a challenge that I ultimately accepted and caused great growth in my own knowledge and skillset.

\section{The Power of Reflection}

Unlike the cohort experience which brought so much collaboration, friendship, and cooperative learning, the dissertation is quite lonely. In some ways that appealed to me; one of my top five strengths, intellection, often times drives me to want to spend time alone processing 
information. In other ways it was tortuous; my friends, family, and cohort were great cheerleaders, but the actual process of researching and writing was entirely dependent on my own motivation, skills, and time management. This process has made me a much more reflective leader in that I know myself better, and I've discovered a power within me to push forward that I didn't know I had before. Whenever I interact with data in my role as building principal, I see it through the eyes of a scholarly-practitioner. Whenever I read a piece of educational writing, I view it through a critical lens. I manage by fact more than feeling, and I am constantly showering my staff with educational research that can improve their classroom instruction.

\section{The Power of Connection}

The dissertation process, and the ELPA program in general, has greatly increased my connection to other leaders across the state of Missouri. From reaching out to like-minded leaders who have similar research interests, to commiserating with those who have gone before me, the dissertation process brings motivated leaders together through common experience. During the dissertation process, I accepted a head principal position. As I end the dissertation process, I have accepted an assistant superintendent position. In both cases, the leaders who hired me are graduates of this doctoral program. I don't think that's a happy accident. My dissertation, and my contribution to practice, will continue to increase my connections to educational leaders across the state.

\section{Dissertation Process Impact on Scholarship}

I became a teacher because I love learning. I would spend hours researching and planning my lessons, never wanting to repeat a classroom activity, always wanting to try something new. As I left the classroom for a job as an assistant high school principal, I think I lost myself a little bit in the transition. There were no more lessons to plan or new learning 
activities to try, far from the trenches of teaching I was quickly enveloped into the world of middle management. From the outside I still appeared to be a learner at heart, sharing interesting articles and leading professional development for my staff, but for the most part I was just surviving on caffeine and to-do lists.

This program brought me (sometimes kicking and screaming) out of the daily rhythm of which I had grown accustomed, and challenged me to be more than a leader - to be a scholar. I distinctly remember my first experience with my dissertation as a purely negative one; at one point during that first summer of cohort 11 (2017), the instructional team had all 90 of us stand up and move to a specific part of the room according to how committed we were to our research interests. On the left, a group of students stood who were absolutely sure of their research interests and dissertation topics; in the middle was the largest group who had a good idea but had not quite decided on the specific direction of their research interests. I was in the smallest group on the right — the "lost souls" who had no idea or general direction on their research interests.

Fortunately, the dissertation process only got better. The biggest way it impacted me as a scholar is the intellectual transformation discussed by Perry (2016) in his study of the cohort doctoral process. My thinking has changed in that I study education through a broader perspective, seeing the human, structural, political and symbolic nature of different issues. I understand the power of research as an impetus for real social change. I am not satisfied simply to believe something, I must read, analyze, and understand it on an intellectual level. I appreciate the power of the dissertation to cause an evolution in my development as a learner.

As I move forward from this experience, I will carry with me the pride of accomplishment, but also the challenge of continuing to learn and lead with both my head and my heart. 


\section{References}

Acree, L., Gibson, T., Mangum, N., Wolf, M. A., Kellogg, S., \& Branon, S. (2017). Supporting school leaders in blended learning with blended learning. Journal of Online Learning Research, 3 (2), 105-143.

Aguinis, H., Gottfredson, R. K., \& Joo, H. (2012). Delivering effective performance feedback: The strengths-based approach. Business Horizons, 55, 105-111.

Anast-May, L., Penick, D., Schroyer, R., \& Howell, A. (2011). Teacher conferencing and feedback: Necessary but missing. International Journal of Educational Leadership Preparation, 6(2), 19-23.

Bada, S. O. (2015). Constructivism learning theory: A paradigm for teaching and learning. Journal of Research \& Method in Education, 5(6), 66-70. doi:10.9790/7388-05616670

Bass, B. M., \& Avolio, B. J. (1994). Improving organizational effectiveness through transformational leadership. Thousand Oaks, CA: SAGE.

Beck, C. D. (2014). Antecedents of servant leadership: A mixed methods study. Journal of Leadership \& Organizational Studies, 21, 299-314. doi:10.1177/1548051814529993

Berger, P., \& Luckmann, T. (1967). The Social Construction of Reality: A Treatise in the Sociology of Knowledge. Garden City, NY: Doubleday.

Bogdan, R. C., \& Biklen, S. K. (1992). Qualitative research for education: An introduction to theory and methods. Boston: Allyn and Bacon.

Bolman, L. G., \& Deal, T. E. (2013). Reframing organizations: Artistry, choice and leadership (5th ed.). San Francisco, CA: Jossey-Bass.

Boghossian, P. (2006). Behaviorism, Constructivism, and Socratic Pedagogy. Educational Philosophy and Theory, 38(6), 713-722. 
Brandt, R. (1992). On rethinking leadership: A conversation with Tom Sergiovanni. Educational Leadership, 49(5), 46-49.

Bray, B. A., \& McClaskey, K. A. (2014). Make learning personal: the what, who, wow, where and why. Boston, MA: Corwin.

Buckingham, D., \& Clifton, D. O. (2001). Now, discover your strengths. New York: The Free Press.

Calabrese, R. L, \& Zepeda, S. J. (1999). Decision-making assessment: Improving principal performance. International Journal of Education Management, 13(1), 6-13.

Carter, D., \& Page, C. (2009). Strengths coaching. In S. J. Lopez (Ed.), The Encyclopedia of Positive Psychology (pp.xxx-xxx). Hoboken, NJ: Wiley-Blackwell.

Christensen Institute (2016). What is Blended Learning? Retrieved from https://www.christenseninstitute.org/blended-learning/

Clifton, D. O., \& Harter, J. K. (2003). Investing in strengths. In K. S. Cameron, J. E. Dutton, \& R. E. Quinn (Eds.), Positive organizational scholarship: Foundations of a new discipline, (pp. 111-121). San Francisco: Berrett-Koehler Publishers, Inc.

Cogan, M. (1973). Clinical supervision. Boston: Houghton Mifflin.

Collins, J. (2011). Level 5 leadership: The triumph of humility and fierce resolve. In Harvard Business Review (Eds.). HBR's 10 must reads: On leadership (pp. 115-136). Boston, MA: Harvard Business Review Press.

Cooperrider, D. W., \& Srivasta, S. (2017) Appreciative inquiry in organizational life. Research in Organization Change and Development. Emerald Publishing Limited.

Creswell, J. W. (2014). Research design. Los Angeles: SAGE.

Creswell, J. W. (2016). Thirty essential skills for the qualitative researcher. Los Angeles: SAGE. 
Creswell, J. W., \& Miller, D. L. (2000). Determining validity in qualitative inquiry. Theory Into Practice, 39:3, 124-130, doi: 10.1207/s15430421tip3903_2

Department of Elementary and Secondary Education (2018). Model leader standards and indicators: principal standards. Retrieved from https://dese.mo.gov/sites/default/files /PrincipalStandards.pdf

Dewey, J. (1938). Experience and education. New York: Collier.

Dewey, J. (1998). Experience and Education: the 60 $0^{\text {th }}$ anniversary edition. Lecture Part. Kappa Delta Pi, International Honor Society in Education.

Elleven, R. K. (2007). Appreciative inquiry: A model for organizational development and performance improvement in student affairs. Education, 127(4). 451-455.

Fensham, P. J., Gunstone, R. F., \& White, R. T. (2012). The content of science: A constructivist approach to its teaching and learning. New York: Routledge.

Fenton, A., Walsh, K., Wong, S., \& Cumming, T. (2014). Using strengths-based approaches in early years practice and research. International Journal of Early Childhood, 47(1), 27-52.

Fosnot, C. T., \& Perry, R. S. (2005). Constructivism: A psychological theory of learning. In C. Fosnot (Ed.), Constructivism: Theory, perspectives, and practice (2 ${ }^{\text {nd }}$ ed.). (pp. 8-38). New York: Teachers College Press.

Friesen, N. (2012). Report: defining blended learning. Retrieved from https://www.normfriesen.info/papers/Defining_Blended_Learning_NF.pdf.

Fritzberg, G. J. (2004). Revise and resubmit: a critical response to Title One of the No Child Left Behind Act. Journal of Education, 184(1), 69-87. doi: 10.1177/002205740418400106 
Gentles, S. J., Charles, C., Ploeg, J., \& McKibbon, K. (2015). Sampling in qualitative research: Insights from an overview of the methods literature. The Qualitative Report, 20(11), 1772-1789. Retrieved from https://nsuworks.nova.edu/tqr/vol20/iss11/5

George, B., Sims, P., McLean, A. N., \& Mayer, D. (2011). Discovering your authentic leadership. In Harvard Business Review (Eds.). HBR's 10 must reads: On leadership (pp. 163-177). Boston, MA: Harvard Business Review Press.

Golafshani, N. (2003). Understanding Reliability and Validity in Qualitative Research. The Qualitative Report, 8(4), 597-606. Retrieved from https://nsuworks.nova.edu/tqr /vol8/iss $4 / 6$

Goldhammer, R. (1969). Clinical supervision: Special methods for the supervision of teachers. New York: Holt, Rinehart \& Winston.

Grissom, J. A, Egalite, A. J, and Lindsay, C .A. (2021). How principals affect students and schools: A systematic synthesis of two decades of research. New York: The Wallace Foundation. Available at http://www.wallacefoundation.org/principalsynthesis

Guignon, C. (2002). Hermeneutics, authenticity, and the aims of psychology. Journal of Theoretical and Philosophical Psychology, 22. 83-102.

Hallinger, P. (1992). The evolving role of American principals: From managerial to instructional to transformational leaders. Journal of Educational Administration, 30(3), 35-48. doi: $10.1108 / 09578239210014306$

Hallinger, P. (2003). Leading educational change: reflections on the practice of instructional and transformational leadership. Cambridge Journal of Education, 33(3), 329-351.

Hattie, J. (2008). Visible learning. Abindon, Oxon: Routledge. 
Hiemstra, D., \& Van Yperen, N. W. (2015). The effects of strength-based versus deficit-based self-regulated learning strategies on students' effort intentions. Motivation and Emotion, $39(5), 656-668$.

Hodges, T. D., \& Clifton, D. O. (2004). Strengths-based development in practice. In P. Linley \& S. Joseph (Eds.), Positive psychology in practice (pp. 256-268). Hoboken, NJ: John Wiley \& Sons, Inc.

Hodges, T. D., \& Harter, J. K. (2005). A review of the theory and research underlying the StrengthsQuest program for students. Educational Horizons. 83(3). 190-201.

Horng, E. L., Klasik, D., \& Loeb, S. (2009). Principal time-use and school effectiveness. (School Leadership Research Report No. 09-3). Stanford, CA: Stanford University, Institute for Research on Education Policy \& Practice.

Hvidston, D. J., \& Range, B. G. (2015). The view of novice and late career principals concerning instructional and organizational leadership within their evaluation. Planning and Changing, 46(1/2), 109-126.

Korthagen, F. A. J. (2004). In search of the essence of a good teacher: Towards a more holistic approach in teacher education. Teaching and Teacher Education, 20, 77-97. doi:10.1016/j.tate.2003.10.002

Lakeland Public Schools (2019). Lakeland Public Schools strategic priorities. Retrieved from Lakeland Public Schools district website: https://Lakelandschools.org/district/board_of_education/strategic_plan.

Leadership Research Report No. 09-3). Stanford, CA: Stanford University, Institute for Research on Education Policy \& Practice. 
Lincoln, Y. S., \& Guba, E. G. (1985). Naturalistic Inquiry. Thousand Oaks, CA, US: Sage Publications, Inc

Lord, R. G., DeVader, C. L., \& Alliger, G. M. (1986). A meta-analysis of the relation between personality traits and leadership perceptions: An application of validity generalization procedures. Journal of Applied Psychology, 71, 402-410.

Mahoney, M. J. (2002). Constructivism and positive psychology. In C. R. Snyder \& S. J. Lopez (Eds.), Handbook of positive psychology (pp. 745-750). New York, NY: Oxford University Press.

Mann, R. D. (1959). A review of the relationship between personality and performance in small groups. Psychological Bulletin, 56, 241-270.

Marshall, K. (2005). It's time to rethink teacher supervision and evaluation. Phi Delta Kappan, 86(10), 725-735. doi: 10.1177/003172170508601004

Marshall, K. (2012). Fine-tuning teacher evaluation. Educational Leadership, 70(3), 50-53.

Martin, J. (2006). Self research in educational psychology: A cautionary tale of positive psychology in action. The Journal of Psychology, 140(4), 307-316.

Marzano, R. J. (2007). The art and science of teaching: A comprehensive framework for effective instruction. Association for Supervision and Curriculum Development.

Marzano, R. J., Frontier, T., \& Livingston, D. (2011). Effective supervision: Supporting the art and science of teaching. New York: ASCD.

Merriam, S. B. (1998). Qualitative research and case study applications in education. San Francisco, CA: Jossey-Bass

Merriam, S. B., \& Tisdell, E. B. (2016). Qualitative research: A guide to design and implementation $\left(4^{\text {th }}\right.$ ed.). Hoboken, NJ: John Wiley \& Sons, Inc. 
Miller, A. (2008). A critique of positive psychology—or "the new science of happiness". Journal of Philosophy of Education, 42(3/4). 591-608.

Miron, G., \& Shank, M. G., \& Davidson, C. (2018). Full-time virtual and blended schools: enrollment, student characteristics, and performance. Boulder, CO: National Education Policy Center.

Missouri Leadership Development System (2016). Missouri leadership development system emerging leader facilitator guide. Retrieved from https://ccsso.org/sites/default/files/2017-10/MLDS\%20Emerging\%20Level \%20Facilitator\%20Guide\%2011.1-PRINT_0.pdf

Myers, D. G. (2000). The funds, friends, and faith of happy people. American Psychologist, 55. 56-67.

National Policy Board for Educational Administration (2015). Professional standards for educational leaders. Retrieved from https://ccsso.org/sites/default/files/201710/ProfessionalStandardsforEducationalLeaders2015forNPBEAFINAL.pdf

Network for Educator Effectiveness (2019). Comprehensive educator evaluation. Retrieved June 20, 2019, from https://neeadvantage.com/comprehensive-educator-evaluation/

Neumerski, C. M. (2012). Rethinking instructional leadership, a review: What do we know about principal, teacher, and coach instructional leadership, and where should we go from here. Educational Administration Quarterly, 49(2), 310-347. doi:10.1177/001316x12456700

Nidus, G., \& Saddler, M. (2011). The principal as formative coach. Educational Leadership, 69 (2), 30-35.

Northouse, P. G. (2016). Leadership: theory and practice. Los Angeles: SAGE. 
O’Donnell, R. J., \& White, G. P. (2005). Within the accountability era: Principals' instructional leadership behaviors and student achievement. NASSP Bulletin, 89(645), 56-71.

Ofman, D. (2000). Core qualitities: A gateway to human resources. Schiedam: Scriptum.

Ovando, M. N. (2001). Teachers' perceptions of a learner-centered teacher evaluation system. Journal of Personnel Evaluation in Education, 15(3), 213-231.

Ovando, M.N., \& Ramirez, A., Jr. (2007). Principals’ instructional leadership within a teacher performance appraisal system: Enhancing students' academic success. Journal of Personnel Evaluation in Education, 200 (1-2), 85-110.

Patton, M. Q. (1990). Qualitative evaluation and research methods (2nd ed.). Thousand Oaks, CA, US: Sage Publications, Inc.

Patton, M. Q. (2015). Qualitative research and evaluation methods ( ${ }^{\text {rd }} \mathrm{ed}$.). Thousand Oaks, CA: Sage.

Park, N., \& Peterson, C. Positive psychology and character strengths: Application to strengthsbased school counseling. Professional School Counseling, 12(2), 85-95. doi: $10.1177 / 2156759 X 0801200214$

Pluskota, A. (2014). The application of positive psychology in the practice of education. SpringerPlus, 3(147), 1-7.

Rath, T. (2007). Strengths finder 2.0. New York: Gallup Press.

Rooke, D., \& Torbert, W. R. (2005). Seven transformations of leadership. Harvard Business Review, 83(4), 66-76. In Harvard Business Review (Eds.). HBR's 10 must reads: On leadership (pp. 137-161). Boston, MA: Harvard Business Review Press.

Rutherford Learning Group (2018). 7 Tools for Developing Teachers. Rutherforld Learning Group. 
Rutherford, M. (2018, June). A logic model for instructional leadership. Presentation at the Missouri New Administrators' Conference, Columbia, MO.

Schorr, J., \& McGriff, D. (2012). Future schools: blending face-to-face and online learning. Education Digest: Essential Readings Condensed for Quick Review, 77(5), 3037.

Seidman, I. (2006). Interviewing as qualitative research: a guide for researchers in education and the social sciences. Columbia University: Teachers College Press.

Seligman, M. E. P. (2002). Positive psychology, positive prevention, and positive therapy. In C. R. Snyder \& S. J. Lopez (Eds.), Handbook of positive psychology (pp. 745-750). New York, NY: Oxford University Press.

Seligman, M. E. P., \& Csikszentmihalyi, M. (2000). Positive psychology: An introduction. American Psychologist, 55(1), 5-14.

Shaha, S. H., Glassett, K. F., \& Copas, A. (2015). The impact of teacher observations with coordinated professional development on student performance: A 27-state program evaluation. Journal of College Teaching \& Learning, 12(1), 55-64.

Stake, R. E. (2010). Qualitative research: Studying how things work. New York: The Guilford Press.

Stogdill, R. M. (1948). Personal factions associated with leadership: A survey of the literature. Journal of Psychology, 25, 35-71.

The Wallace Foundation (2010). Reimagining the job of leading schools. Journal of Staff Development, 31(2), 11-17.

Toch, T., \& Rothman, R. (2008). Rush to judgment: teacher evaluation in public education. Education Sector Reports. 
Tschannen-Moran, M., \& Tschannen-Moran, B. (2011). Taking a strengths-based focus improves school climate. Journal of School Leadership, 21 (3), 422-448.

Tucker, C. R. (2013). The basics of blended instruction. Educational Leadership, 70 (6), 57-60.

Tucker, C. R. (2020). Balance with blended learning: partner with your students to reimagine learning and reclaim your life. Thousand Oaks, CA: Corwin.

Turner, N., Barling, J., \& Zacharatos, A. (2002). Positive psychology at work. In C. R. Snyder \& S. J. Lopez (Eds.), Handbook of positive psychology (pp. 715-728). New York, NY, US: Oxford University Press.

Ültinar, E. (2012). An epistemological glance at the constructivist approach: Constructivist learning in Dewey, Piaget, and Montessori. International Journal of Instruction, 5(2), 195-212.

Van Woerkom, M., \& Meyers, M. C. (2015). My strengths count! Effects of a strengths-based psychological climate on positive affect and job performance. Human Resource Management, 54(1), 81-103.

Vogotsky, L. (1986). Language and thought. Cambridge, MA: MIT Press.

Walker, K., \& Carr-Stewart, S. (2004). Learning leadership through appreciative inquiry. International Studies in Educational Administration, Journal of Commonwealth Council for Educational Administration and Management, 32 (1), 72-86.

The Wallace Foundation (2010). Reimagining the job of leading schools. Journal of Staff Development, 31(2), 11-17.

Weisberg, D., Sexton, S., Mulhern, J., \& Keeling, D. (2009). The widget effect: Our national failure to acknowledge and act on difference in teacher effectiveness. Education Digest: Essential Readings Condensed for Quick Review, 75(2). 31-35. 
Whitaker, B. (1997). Instructional leadership and principal visibility. The Clearing House, 70(3), 155-156.

Wind, S. A., Tsai, C. L., Grajeda, S. B., \& Bergin, C. (2017). Principals' use of rating scale categories in classroom observations for teacher evaluation. School Effectiveness and School Improvement, 29(3), 485-510. doi: 10.1080/09243453.2018.1470989

Winseman, A. L. (2002). Doing what they do best. Gallup Management Journal, 2(3), 1-4

Yazan, B. (2015). Three approaches to case study methods in education: Yin, Merriam, and Stake. The Qualitative Report, 20(2), 134-152. Retrieved from https://nsuworks.nova.edu/tqr/vol20/iss2/12

Yin, R. K. (2014). Case study research: Design and methods $\left(5^{\text {th }}\right.$ ed.). Thousand Oaks, CA: Sage.

Zepeda, S. J. (2006). Classroom-based assessments of teaching and learning. In J. H. Stronge (Ed.), Evaluating teaching: A guide to current thinking and best practice, $2^{\text {nd }} \mathrm{ed} . \mathrm{pp} .101-$ 124. Thousand Oaks, CA: Corwin. 


\section{Appendix A: Semi-Structured Interview Prompts}

Interview 1: Leader Background and Identity

1. Describe your journey to become a building leader.

2. How would you describe your leadership style?

3. How has your training in strengths-based coaching impacted your leadership and how you work with your followers?

Interview 2: Structure of Strengths-Based Coaching and Feedback

1. How do you implement strengths-based coaching on a daily basis?

2. How do you fit coaching into the workflow of your other daily duties?

3. What are some of the challenges to implementing strengths-based coaching in practice?

4. Walk me through a coaching session from start to finish (what does it look/sound like, how is it structured, what resources do you rely on)?

Interview 3: Making Sense of Strengths-Based Coaching and Feedback

1. What have you learned from implementing strengths-based coaching and feedback about yourself?

2. What have you learned about teacher development and evaluation?

3. What are some of the benefits, what are some of the limitations of this coaching model?

4. What do you hope to do in the future regarding strengths-based coaching? 


\section{Appendix B: Strengths-Based Coaching Observation Protocol}

Research Participant:

Date and Time:

\section{Objective Notes}

\section{Subjective Observations}

Environment/Context

\begin{tabular}{|l|l|}
\hline & \\
\hline
\end{tabular}

Purpose

\begin{tabular}{|l|l|}
\hline & \\
\hline
\end{tabular}

Coaching Observation 1

\begin{tabular}{|l|l|}
\hline & \\
\hline
\end{tabular}

Coaching Observation 2

\begin{tabular}{|l|l|}
\hline & \\
\hline & \\
\hline \multicolumn{2}{|c|}{ Coaching Observation 3}
\end{tabular}

\begin{tabular}{|l|l|}
\hline & \\
\hline & \\
\hline Coaching Observation 4 \\
\hline
\end{tabular}

\begin{tabular}{|l|l|}
\hline & \\
\hline Coaching Observation 5 \\
\hline & \\
\hline Coaching Observation 6 \\
\hline
\end{tabular}




\section{VITA}

Staci Johnson has been a public-school educator in Missouri for the last fifteen years. She attended the University of Central Missouri in Warrensburg, where she earned a Bachelor of Science in Education degree in Speech Communication and Theatre and a minor in Spanish. While working as a high school speech and debate teacher, Mrs. Johnson also earned a Master's degree in educational leadership from the same institution. In the classroom, Mrs. Johnson has always had a great passion for improving her own craft and developing others to their fullest potential.

In 2014, Mrs. Johnson earned a Specialist degree in Educational Leadership and Policy Analysis from the University of Missouri, and left the classroom to begin her principalship. For the last seven years, she has been working as a high school administrator. Her research and professional interests include teacher and leader development, classroom instructional strategies, and strengths-based leadership. Next year, Dr. Johnson will advance to the superintendency as an assistant superintendent in charge of curriculum, instruction, and assessment. She plans to continue her research in the field of leadership development and hopes to inspire leaders and empower teachers to improve learning for all Missouri students 